\title{
Retaining structures: displacement and design
}

\author{
B. SIMPSON*
}

The quest for rational methods of designing retaining structures has been pursued for many decades. The existing British code of practice was first published in 1951 and a committee attempting to revise it has been sitting for about 20 years; the record of other European countries is little better. A major reason for the difficulty lies in the importance of soil-structure interaction to the behaviour of retaining walls, and in particular the significance of displacement in governing the acceptability of a particular design.

The Eurocodes, which are currently under development will adopt a partial factor method for establishing safety and, incidentally, serviceability. At the same time, an editing group working on the British code has concentrated attention on serviceability, but its recommendations for calculations are rather similar to those of the Eurocode. The approaches proposed by both these groups will lead to some differences in the designs adopted for construction, when compared with conventional British design. The background to these approaches is discussed in this Paper.

In an effort to understand the behaviour of retaining walls, ground movements at many deep excavations have been monitored. Besides aiding understanding of the interaction of ground and walls, this has provided the stimulus for major research and development in fundamental understanding of the stress-strain behaviour of soil. Results of measurements at the excavation for the British Library in London are presented and compared with computed soil movements using both old and new models of soil behaviour.

Largely because of measurements of retaining wall behaviour, it is now widely recognized that most soils exhibit much higher stiffness at very small strains than were measured in traditional laboratory tests on soil specimens. This feature, represented by the $S$-shaped curve, has been incorporated into a new model of soil behaviour which is based on a simple analogue. Despite its simplicity, the analogue leads to predictions of a surprising range of soil properties for both normally consolidated and overconsolidated states. The model is readily incorporated into a finite element program and reproduces the ground movements measured at

* Arup Geotechnics, London.
La recherche de méthodes rationnelles de conception de structures de soutènement a été entreprise depuis des dizaines d'années déjà. La norme britannique actuelle a été publiée pour la première fois en 1951 et un comité travaille sur sa révision depuis environ vingt ans. Les normes des autres pays européens sont à peine meilleures. L'une des difficultés principales réside dans l'importance de l'interaction sol-structure sur le comportement des murs de soutènement et, plus particulièrement, dans l'amplitude du déplacement qui régit l'acceptation ou non d'une structure particulière.

Les normes européenes actuellement à l'étude adopteront une méthode de facteur partiel pour calculer la sécurité et, incidemment, la capacité de service. Parallèlement, un group réductionnel travaillant sur la norme britannique a concentré son attention sur la capacité de service et ses recommandations de calcul sont tout à fait équivalentes à celles de la norme européenne. Les approches proposées par le deux groupes vont conduire à quelques différences entre les formes adoptées pour la construction et celles plus conventionnelles de la norme britannique. La base de ces approches est étudiée dans cet article.

De façon à mieux comprendre le comportement des murs de soutènement, les mouvements du sol ont été enregistrés dans de nombreuses excavations profondes. En plus d'une meilleure compréhension des interactions sol-mur, ces études ont stimulé d'importantes recherches et développements dans la compréhension fondamentale du comportement contrainte-déformation des sols. Les mesures réalisées dans la fouille de la British Library à Londres sont présentées et comparées à des mouvements de sol calculés numériquement à la fois à l'aide d'anciens et de nouveaux modèles de comportement.

En raison de ces mesures de comportement de murs de soutènement, il est aujourd'hui largement reconnu que la plupart des sols présentent, à petites déformations, des raideurs supérieures à celles mesurées sur des échantillons de sol lors d'essais de laboratoire traditionnels. Ce fait, représenté par la 'courbe en $S$ ', a été intégré à un nouveau modèle de comportement des sols basé sur une analogie simple. Malgré sa simplicité, cette analogie conduit à prédire une catégorie suprenante de propriétés des sols pour des états normalement ou surconsolidés. Le modèle est directement incorporé à 
the British Library excavation fairly well, together with those of a deep excavation in soft clay from Singapore. It is used to provide further understanding and justification for the design methods being developed in the European and British codes of practice.

The importance of displacement and strain forms a recurrent theme in the Paper.

KEYWORDS: clays; finite element methods; numerical modelling; retaining walls; soil-structure interaction un programme d'éléments finis et reproduit relativement bien les mouvements de sol mesurés dans la fouille de la British Library, ainsi que ceux mesurés sur une excavation profonde dans des argiles molles de Singapour. Le modèle a été utilisé pour obtenir une compréhension et une justification des méthodes de conception en cours de développement dans les normes européennes et britanniques.

L'importance des déplacements et des déformations est un thème permanent de cet article.

\section{INTRODUCTION}

In the frontispiece to his $\mathrm{PhD}$ thesis, Professor John Burland wrote (Burland, 1967)

Stress is a philosophical concept -deformation is the physical reality.

Engineers are familiar with concepts and calculations involving stresses in materials, but what really matters- - what the public sees-is movement and deformation which lead to damage and danger. This idea forms a link between the topics in this Paper and is also important to the philosophy of modern codes of practice. The Eurocodes, for example, are based on the requirement that designs should be studied at limit statesstates at which their behaviour ceases to be acceptable - which are defined in terms of damage, displacement and appearance.

Nevertheless, calculations used in design and required by codes of practice are mainly based on limit equilibrium methods in which attention is concentratcd on balancing stresses and no explicit account is taken of soil stiffness or deformation. In recent years the finite element method has made it possible to compute equilibrium and deformation together, but this requires a reliable model of soil stress-strain behaviour.

This Paper is concerned with codes of practice, measured deformations and with a model of soil behaviour.

\section{DESIGN BASIS AND FACTORS OF SAFETY}

Codes of practice and factors of safety have a big influence on the lives of many engineers, either because they face the confusion of trying to apply them in a consistent way or because of the considerable commercial implications of the various systems and values.

The British code of practice on earth retaining structures, CP2, is now 40 years old (British Standards Institution 1951). A committee of the British Standards Institution has been sitting for about 20 years in an attempt to revise the code, and this work is not yet complete. The situation in other European countries is little better, though various documents of semi-code status are in common use, notably EAU 1980 (Society for Harbor Engineering and the German Society for Soil Mechanics and Foundation Engineering, 1982) and the Construction Industry Research and Information Association (CIRIA) Report 104 (Padfield \& Mair, 1984). Hong Kong Geoguide 1 (Geotechnical Control Office, 1982) was based on the concepts of CP2 and presented them in a more up-to-date form; a revised draft, based on the partial factor method, has recently been circulated for comment and the basis of its partial factors is discussed by Pang (1992).

The main reason for the difficulty in finalizing codes on retaining walls is that agreement is not easily reached on a method of applying factors of safety which is sufficiently rational to be used consistently. Bolton (1991) has suggested that it would be more rational to avoid the use of factors of safety completely, allowing for uncertainty in parameter values by direct consideration of the possiblc range of values and concentrating on the serviceability requirements of the designs, expressed mainly in terms of limiting displacements. Bolton, Powrie \& Symons (1990a, b) have shown how displacement limits could be related to the proportion of the soil's strength assumed to be mobilized in a limit equilibrium calculation.

In 1985 CIRIA invited designs for retaining walls in two concisely specified situations. The range of wall lengths submitted varied by more than 3 to 1 (Head \& Wynne, 1985) and similar variation has been found in other comparisons in the Nordic countries (Krebs Ovesen, 1984) and, in studies carried out for Eurocode 7 , across Europe. The commercial implications of these variations are quite large.

The goal of consistent, internationally agreed methods of designing structures has obvious commercial relevance in the European free market and has provided the motivation for the drafting of Eurocodes. In the case of retaining walls, any system which will be of sufficient repute to be used in practice will need to satisfy the second goal of rational consistency. 


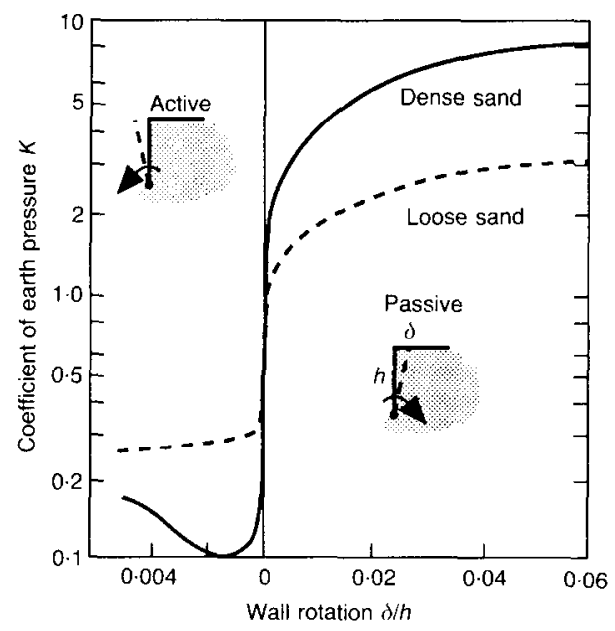

Fig. 1. Relationship between earth pressure and wall rotation measured by Terzaghi for normally consolidated sand (different scales for active and passive)

\section{Mobilization of passive pressure}

British thinking about earth pressures on walls has been greatly influenced by the experimental results published by Terzaghi (1954) and shown in Fig. 1. He rotated a small model wall into or away from a bed of sand -either loose or denscly packed-and recorded the amount of rotation needed to reach the active and passive states. He found that the active state was reached with very little movement, but much more movement was needed to reach the passive state. This has led to the concept that only a small proportion of the passive pressure should be used in design. It is argued that if the wall is proportioned so that this is in equilibrium with the active pressure, then the movement of the wall will be small.

Terzaghi's results were for sand which had not been preloaded and so had an initial coefficient of earth pressure $K_{0}$ of about 0.43. More recently, Potts \& Fourie (1986) carried out a series of computer studies intended to represent overconsolidated clay for which $K_{0}$ could be as high as 2. Their results, shown in Fig. 2 suggested that for these conditions similar amounts of movement wcre rcquired to approach either active or passive conditions. However this conclusion must be treated with caution because the clay was represented as linear elastic until it reached its maximum shear strength; this unrealistic feature might have influenced the results.

Figure 3 shows another important result illustrated by Potts \& Fourie. In most situations where passive pressure is to be mobilized, the ground is at the base of an excavation. This means that overburden has recently been removed from it and it naturally has high hori-

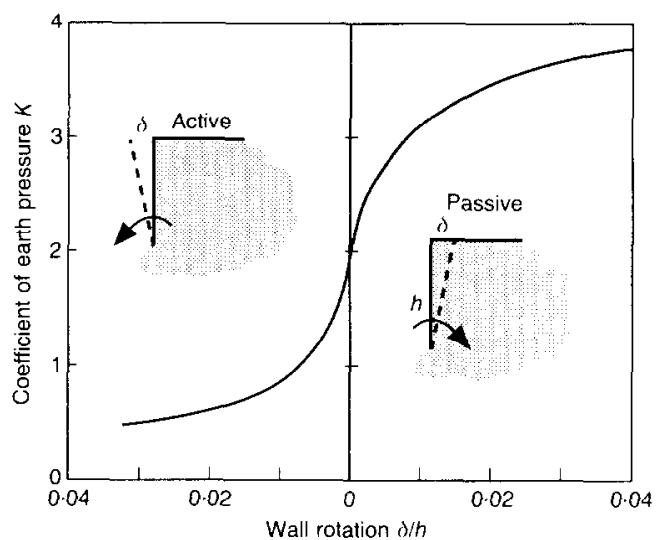

Fig. 2. Relationship between earth pressure and wall rotation computed by Potts \& Fourie (1986) for overconsolidated clay

zontal stresses in relation to its new, reduced vertical stresses. For stiff clay with $K_{0}=2$, the shaded area in Fig. 3 was computed to have reached a passive state, even when the wall was completely prevented from moving. It is clear that beneath an excavation passive pressures develop without large displacement of the wall.

\section{Safety factors in codes of practice}

Most modern codes of practice, including the Eurocodes, are based on the limit state method. In this method, consideration of stability is, in principle, separated from consideration of dis-

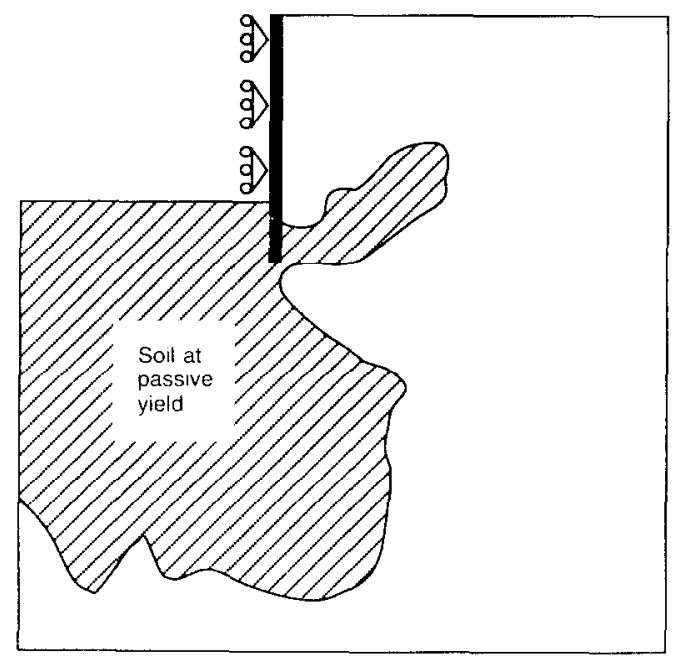

Fig. 3. Zone of soil at passive yield beneath excavation with fully restrained wall, computed by Potts \& Fourie (1986) 
placement in the working state. The codes emphasize the need for factors of safety to ensure that collapse of a structure is extremely unlikely to occur, since the design must have enough in reserve to remain stable while subjected to a reasonable range of unforeseen events.

In general, these codes implicitly assume that displacements will be a secondary problem, related only to minor 'serviceability' limit states, and can be estimated with sufficient reliability by direct, if crude, calculation. However, in the case of retaining walls displacements may be larger than normally expected in concrete or steel structures. If the retained soil supports other structures or services, ground movements could be large enough to cause severe distress to them even though the retaining wall itself is quite stable. The distress may be sufficiently severe to constitute an 'ultimate' limit state, in the definition of the codes.

The best available information about likcly movements of walls comes from past experience and recorded case histories. Displacements can be calculated but both experience and calculations are only useful if the wall being designed will be as remote from collapse as other walls with which it can be compared. The new wall must mobilize a similar proportion of the soil's strength as have others for which there is experience or from which calculation methods have been developed. Thus, apart from ensuring stability, factors of safety used in design of retaining walls have a second important function in controlling the proportion of the soil's strength which is mobilized in the working state, hence limiting displacement.

The factors may be expressed in several ways. The symbols $F_{\mathrm{s}}$ and $F_{\phi}$ will be uscd to represent factors applied to the strength of the soil or to $\tan \phi^{\prime}$, where $\phi^{\prime}$ is the angle of shearing resistance. The Eurocodes use a partial factor $\gamma_{\mathrm{m}}$ which is applied in the same way. In conventional British practice a factor $F_{\mathrm{p}}$ is applied to the passive pressure, generally taken to be the effective pressure only in calculations for the drained state.

Bolton et al. (1990a, b) draw attention to the strength of the soil actually mobilized when the wall is in service, $\phi_{\text {mob }}^{\prime}$ or $c_{\text {mob }}$. Their method relates mobilized strength to an assessment of movement, relying on the availability of high quality test data for the soils involved. Mobilized strength can be related back to the peak strength, or perhaps to the critical state strength of the soil by factors which are used like safety factors, but they are better understood as serviceability or mobilization factors.

Generally, the partial factors $\gamma$ are defined in terms of making collapse sufficiently unlikely, while the idea of mobilized strength is related to control of movement. In the Author's view, both these aims must be achieved; the choice of symbol is not important.

\section{Safety factors in design of retaining walls}

Factors of safety used for the design of retaining walls can be defined in a number of ways, of which three are illustrated in Fig. 4. Method (a) is based on Terzaghi's finding that passive pressure required more movement to mobilize it than did active pressure. In this method, the passive pressure used in design is reduced by a factor $F_{\mathrm{p}}$, commonly taken to be 2 . In method (b) the strength of the soil used in the design is reduced by a factor which can have one of the symbols $F_{\mathrm{s}}, F_{\phi}$ or $\gamma_{\mathrm{m}}$. This has the effect of increasing the active pressure and reducing the passive pressure. In both these methods, equilibrium must be achieved with these modified earth pressures, shown as shaded zones in Fig. 4. In either scheme the factors can be chosen both to provide a margin against collapse and/or with the intention of limiting deformation.

CIRIA's Report 104, which is frequently used for design of walls in Britain, provides values for $F_{s}$. The report requires the user to assess 'moderately conservative' values for the strength parameters of the soil and then to apply factors of 1.2 to 1.5 to $\tan \phi^{\prime}$. It notes that 1.5 should usually be used for angles of friction less than $30^{\circ}$, which includes most clays.

Method (c) of Fig. 4 is taken from British Steel's Piling Handbook (1988). It requires equi-

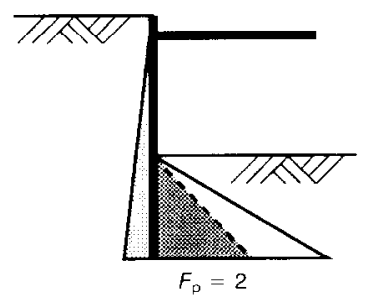

(a)

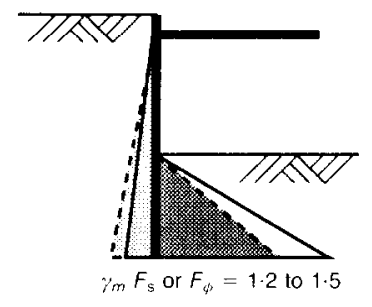

(b)

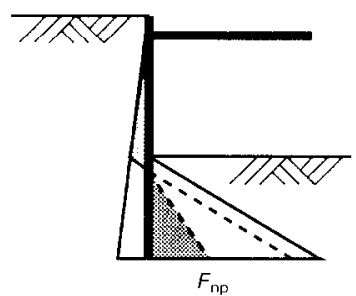

(c)

Fig. 4. Three methods of defining factors of safety for retaining walls 

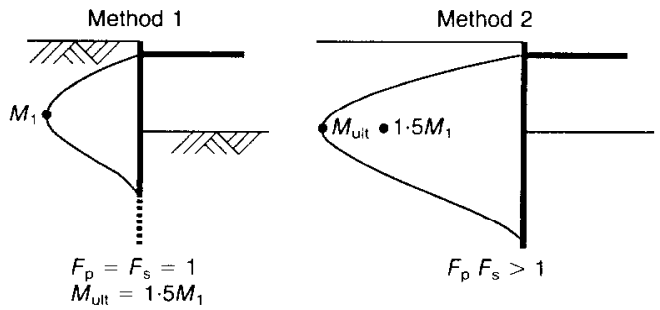

Fig. 5. Two methods of calculating ultimate bending moment for structural design

librium to be achieved having reduced the net passive pressure (the difference between passive and active pressure) by a factor $F_{\text {np }}$. Burland, Potts \& Walsh (1981) showed that the value of $F_{\text {np }}$ has very little effect on the calculated length of the wall, so this method provides very much less safety than do the other methods. Even so, a lot of sheet pile walls are designed in this way and perform satisfactorily, probably because cautious values are generally adopted for the strengths of the soil.

The methods shown in Fig. 4 are used to determine a wall geometry which will ensure stability and perhaps limit wall movement. It is then necessary to determine the stresses in the wall, particularly the maximum bending moment. There are two main methods of doing this in British practice, as illustrated in Fig. 5. In method 1 of Fig. 5, the length of wall already calculated is disregarded and the calculation is repeated using the full soil strength without any reduction factors (i.e. $F_{\mathrm{p}}=F_{\mathrm{s}}=1$ ). The bending moment which is derived is then multiplied by a further safety factor of 1.4 or 1.5 for ultimate limit state design of the wall section. The alternative, method 2, is to use the same soil strength factors as for the stability calculation $\left(F_{\mathrm{p}}, F_{\mathrm{s}}>1\right)$ and use the derived bending moment directly for ultimate limit state design. This often gives a higher bending moment than method 1 .
The Author considers that method 1 is illogical. If the length of wall previously derived is actually needed, pressures acting near its base will have large lever arms and so will inevitably cause large bending moments. Use of method 1 of Fig. 5 is bound to lead to walls which are not strong enough to use their length. They are either unnecessarily long or not sufficiently strong.

\section{An example}

Figure 6 shows an example representing a propped, embedded wall with some assumed soil strength parameters which might represent London Clay. To keep the example simple the water table was assumed to be near ground level in the retained soil, with a water table also at the excavated surface. Water pressure was assumed to vary linearly along the surface of the wall between the two water tables. A $10 \mathrm{kPa}$ surcharge was placed on the retained side.

Assuming earth pressures increase linearly with depth, the wall would be on the point of failure if it was $15.2 \mathrm{~m}$ long and the bending moment would then be $1148 \mathrm{kNm} / \mathrm{m}$, which will be referred to as $M_{1}$, since the factor of safety would be 1.0 , by any of the definitions in Fig. 4 . Other calculated bending moments will be considered as ratios of $M_{1}$.

If the length of the wall is determined using $F_{\mathrm{p}}=2$, the wall is much longer $(21.8 \mathrm{~m})$ and the bending moment derived from the same calculation is $2255 \mathrm{kNm} / \mathrm{m}$, equal to $1.96 M_{1}$. A factor of $F_{\mathrm{s}}=1.5$ on $\tan \phi^{\prime}$ gives a similar design ( $21.3 \mathrm{~m}$ length and $2 \cdot 19 M_{1}$ ). However, it would be common practice in Britain to use method 1 of Fig. 5 to calculate bending moments. The calculated bending moments around $2 M_{1}$ would be disregarded and instead $1.4 M_{1}$ to $1.5 M_{1}$ would be adopted for ultimate limit state design of the wall structure.

In principle, this approach follows the ideas of Rowe (1955) who noted that for flexible retaining

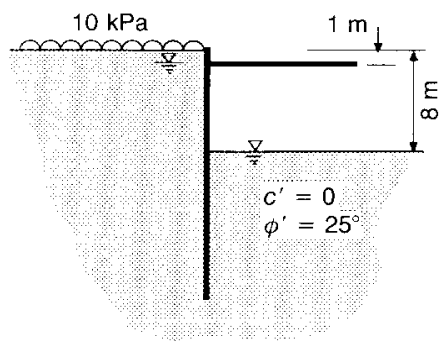

\begin{tabular}{|c|c|c|}
\hline $\begin{array}{l}\text { Factor of } \\
\text { safety }\end{array}$ & $\begin{array}{l}\text { Length: } \\
\mathrm{m}\end{array}$ & $\begin{array}{l}\text { Bending moment } \\
M: \mathrm{kNm} / \mathrm{m}\end{array}$ \\
\hline$F=1$ & $15 \cdot 2$ & $M_{1}=1148$ \\
\hline$F_{p}=2$ & 21.8 & 2255 \\
\hline$F_{\psi}=1.5$ & $21 \cdot 3$ & 2510 \\
\hline$F_{\phi}=1.2$ & $17 \cdot 4$ & 1550 \\
\hline CIRIA 104 & $21 \cdot 3$ & $\begin{array}{l}1722 \\
\text { Potts \& Fourie }\end{array}$ \\
\hline $\begin{array}{l}F_{\phi}=1 \cdot 2 \\
10 \% \text { extra } \\
\quad \text { excavation }\end{array}$ & $19 \cdot 5$ & 2117 \\
\hline Full passive & $19 \cdot 5$ & 2586 \\
\hline
\end{tabular}

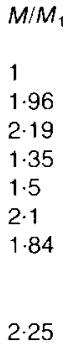

Fig. 6. Calculated lengths and bending moments for an embedded retaining wall using differing factors of safety 
structures earth pressures tend to become redistributed in a manner which reduces bending moments. He proposed reduction factors to be applied to bending moments which were calculated using full factors of safety and linear distributions of earth pressure. These concepts were developed in relation to the behaviour of flexible sheet pile walls in granular soils, for which the active condition is reached in the retained soil with small movement.

Stiff clays generally have high initial coefficient of earth pressure $K_{0}$ and require larger strains to mobilize their strength than do gramular soils. Numerical analyses such as the work of Potts \& Fourie (1986), have suggested that passive restraint beneath an excavation will be fully mobilized, but the earth pressure in the retained soil will also remain significantly above the active limit if the wall is sufficiently long and stiff. In this case, the bending moment in service may exceed $2 M_{1}$.

\section{Factored strength and unplanned excavation}

These concepts are currently under discussion in two code committees: the drafting panel of Eurocode 7 and an editing group working on the British Standards Institution (BSI) code on retaining structures. Eurocode 7 first defines the characteristic value of the strength of the soil, to which a partial factor is applied to derive a design value to be entered into calculations. The definition of characteristic value is contentious, being intended to lead to a realistic but cautious assessment of the strength of the soil in its field situation.

The current draft of Eurocode 7 indicates that the partial factor on $\tan \phi^{\prime}$ will probably be in the range $1 \cdot 2-1 \cdot 25$, and that on $c^{\prime}$ or $c_{\mathrm{u}}$ in the range $1 \cdot 5-1 \cdot 8$. The precise values should, in principle, be decided separately for each nation, but in practice it may prove difficult to reject any consensus view which may emerge. These factors on strength are to be used with unit factors on dead loads and small factors on variable loads, so the partial factors applied to soil strength are almost the only safety factors for many retaining wall problems. In effect they are equivalent to the strength factor $F_{\mathrm{s}}$ or the mobilization factor mentioned earlier. This system has no direct equivalent to the factor on passive pressure or on net pressure.

Calibration studies carried out by the Author (unpublished) and by Pang (1992) suggest that this approach will not change the designs obtained for gravity retaining walls significantly and these are not discussed further.

This Paper is concerned mainly with retaining walls in clays, but one issue related to dense granular materials will be noted here because it may influence the overall scheme of safety factors. In Fig. 7, wall $\mathrm{A}$, penetrating $1.25 \mathrm{~m}$ into a soil with a high angle of friction, has a factor of safety of unity, so its design would not be acceptable by any of the methods in Fig. 4. Wall B, penetrating $2 \mathrm{~m}$, would be acceptable by current British standards, but wall $\mathrm{C}$ is theoretically on the point of failure. Walls $B$ and $C$ have the same length, but the excavation at wall $C$ is $0.5 \mathrm{~m}$ deeper. When the passive material has a high angle of friction very little penetration is needed to achieve normally specified factors of safety, yet the safety could easily be removed by a relatively minor event (human activity or natural erosion) near the base of the wall. For this reason both the Eurocode panel and the present BSI editing group are considering the requirement that an upper layer of passive soil should be disregarded in calculations. In practice, redistribution of active earth pressure towards the prop might make any of the walls in Fig. 7 slightly safer than simple calculations suggest, but the general argument presented here still holds.

In undrained clays it is normal practice to treat the upper metre or so of clay very cautiously and a similar approach is appropriate in other soil

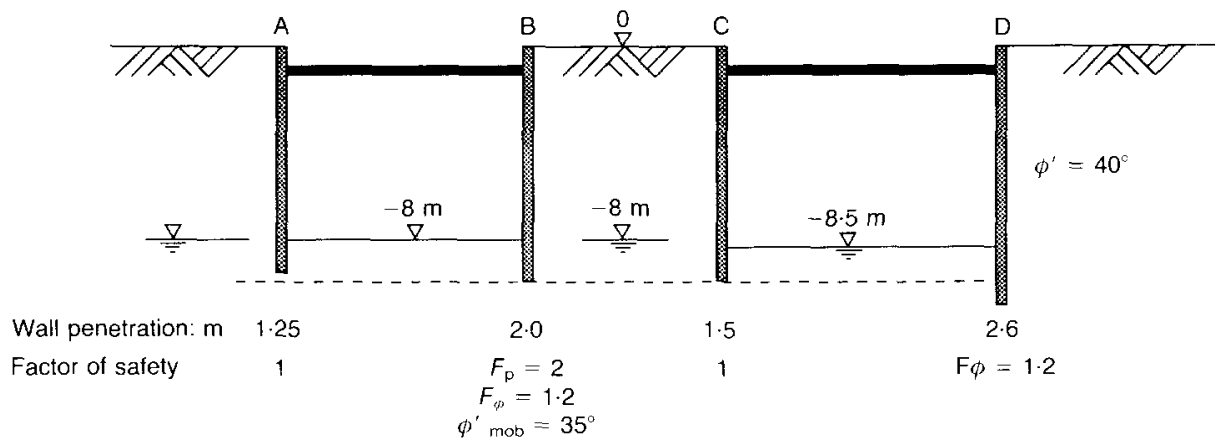

Fig. 7. Propped embedded retaining wall in frictional soil 
types when a thin top layer of passive soil is particularly important. It might be wise to disregard it in design. This constitutes an additional safety element which will influence the required values of other factors and also makes it more appropriate to adopt a uniform factor on strength across a wide range of angles of friction.

The Eurocode 7 panel and the BSI editing group have approached the question of factor of safety from two different philosophies, but their current proposals (still under debate) are fairly similar in practical application. Their main features are as follows.

(a) A factor of about $1 \cdot 2$ is applied to tan $\phi^{\prime}$, and this is combined with a requirement to disregard the top layer of passive soil, which could be specified as $0.5 \mathrm{~m}$ or as $10 \%$ of the retained height of a cantilever or of the height below the lowest prop. In clays, these two items together will be equivalent to a factor on $\tan \phi^{\prime}$ of about 1.3.

(b) The codes will probably specify a minimum surcharge to be assumed as part of the design, at least for the ultimate limit state check.

(c) They will also require a realistic assessment of the maximum bending moment which can occur in service. In some cases this could be considerably in excess of the values calculated as part of the initial stability analysis of the wall and could well exceed the values currently obtained by application of CIRIA Report 104.

(d) More detailed soil-structure interaction analysis is permitted, even encouraged, and in some cases this could yicld lower design bending moments.

The broad implications of these proposals will be that generally in clays walls would be somewhat shorter, but they will be slightly longer in dense granular soils. Stiff concrete walls in clays will be required to be stronger, but they may cost less because of their reduced length.

Adopting shorter walls in clays will inevitably increase the risk of rotational failure and displacements in service will also be greater. However, this statement has no significance until the magnitudes of the risks and displacements are assessed. With regard to rotational failure CIRIA Report 104 concluded that use of $F_{\phi}=1.2$ could be regarded as normal practice for angles of friction greater than $30^{\circ}$ where the results are not much different from the older method applying $F_{\mathrm{p}}=2$. Furthermore, sheet pile walls designed to the net pressure method have low real factors of safety but generally perform satisfactorily. Since the angles of shearing resistance of clay soils are no more uncertain than those of granular soils, it can be concluded that the risk of rotational failure is not unacceptably high for a design based on $F_{\phi}=1 \cdot 2-1 \cdot 3$.

For the example in Fig. 6, a design using $F_{\phi}=$ 1.2 and disregarding the top $0.7 \mathrm{~m}$ of passive soil yields a length of $19.5 \mathrm{~m}$, rather shorter than the more traditional British lengths. The bending moment is higher $\left(1.84 M_{1}\right)$, though still not as large as might be derived by numerical analysis. For these situations the proposal moves in the right direction, but there is a need for further study of this type of problem using both finite element methods and also model tests. The results are sensitive to the relative stiffness of soil and wall, so realistic models of soil behaviour and of the wall itself are essential.

\section{Displacement related to mobilized strength}

Bolton et al. (1990a, b) published a method of relating displacements to the degree of mobilization of the soil strength, or to the strength factor $F_{\phi}$. This could be used to assess the effect on displacements of lower factors of safety and shorter walls in stiff clays. Fig. 8 is derived using their method for a cantilever retaining wall in London Clay assuming water levels at the retained and excavated soil surfaces and an angle of wall friction $\delta$ equal to $\phi^{\prime}$. Calculated wall lengths and displacements are compared for various strength factors $F_{\phi}$ or mobilization factors, taking $F_{\phi}=1.5$ as the base case for comparison. As the factor is reduced towards 1.2 the calculated length of the wall decreases by 10 to $20 \%$ - a significant saving in commercial terms. The displacement of the wall only increases fairly gradually and does not become critical for $F_{\phi} \geqslant$ $1 \cdot 2$. This provides an indication that a strength factor in the range $1 \cdot 2-1 \cdot 3$ will not lead to unacceptable displacements in stiff clays. Again, a more detailed numerical analysis would be helpful, and an example is presented later in this Paper.

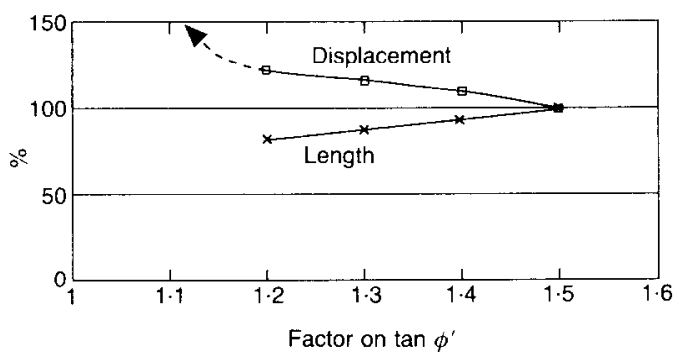

Fig. 8. Variation with factor of safety of length and displacement of cantilever retaining wall in London Clay 


\section{CASE STUDY-THE BRITISH LIBRARY BASEMENT}

The development of understanding of the behaviour of stiff clays has been advanced in recent years by the measurement of ground movements around deep excavations. A sequence of very valuable case studies has been published, including the measurements of ground movement at the Houses of Parliament underground carpark (Burland \& Ilancock, 1977), work by the then Transport and Road Research Laboratory (Symons \& Carder, 1989) and the work at Bell Common and other Papers in the 1984 Géotechnique symposium in print. In the early 1980s construction began on the new building for the British Library, and some aspects of the observations of ground movement at that site will be described here.

The site for the British Library is located on Euston Road adjacent to St Pancras Station in London, as shown in Fig. 9. Across adjacent streets the site is surrounded by buildings, and London Underground's Metropolitan Line lies about $6 \mathrm{~m}$ from its southern boundary just below street level. The Victoria Line and the Northern Line underlie the northern part of the sitc which is referred to as the central area. The south area has four levels of basement and is about $25 \mathrm{~m}$ deep while the central area is up to $15 \mathrm{~m}$ deep.

Figure 10 shows a north-south section through the site. The south area extends through the
London Clay and about $5 \mathrm{~m}$ into the clays of the Woolwich and Reading beds. It was constructed by top-down methods: the underreamed piles were built first leaving cased bores above them into which columns were subsequently placed. Water levels in the chalk aquifer beneath the site have been depressed by purnping during the past two centuries and this has led to reduced piezometric pressures in the clays. Relief wells were constructed so that the foundations and the toes of the retaining wall will not be disrupted as groundwater levels in the aquifer rise in the future. Gound movements around the south area are considered in this Paper.

\section{Early stages of excavation}

The first site activity in 1982 was excavation to about $5 \mathrm{~m}$ depth more or less simultaneously with construction of most of the retaining walls. Inclinometers were cast into the walls, but unfortunately many of them were commissioned after the initial $5 \mathrm{~m}$ excavation had taken place and so they missed the early movement. Next, the bored piles were constructed in the south area leaving $2 \mathrm{~m}$ diameter cased borings above them with the annulus outside the corrugated casing backfilled with pea gravel. Due to financial constraints there was very little activity on site at this stage for about a year. During this period it was noted that the Metropolitan Line tunnel, which had settled

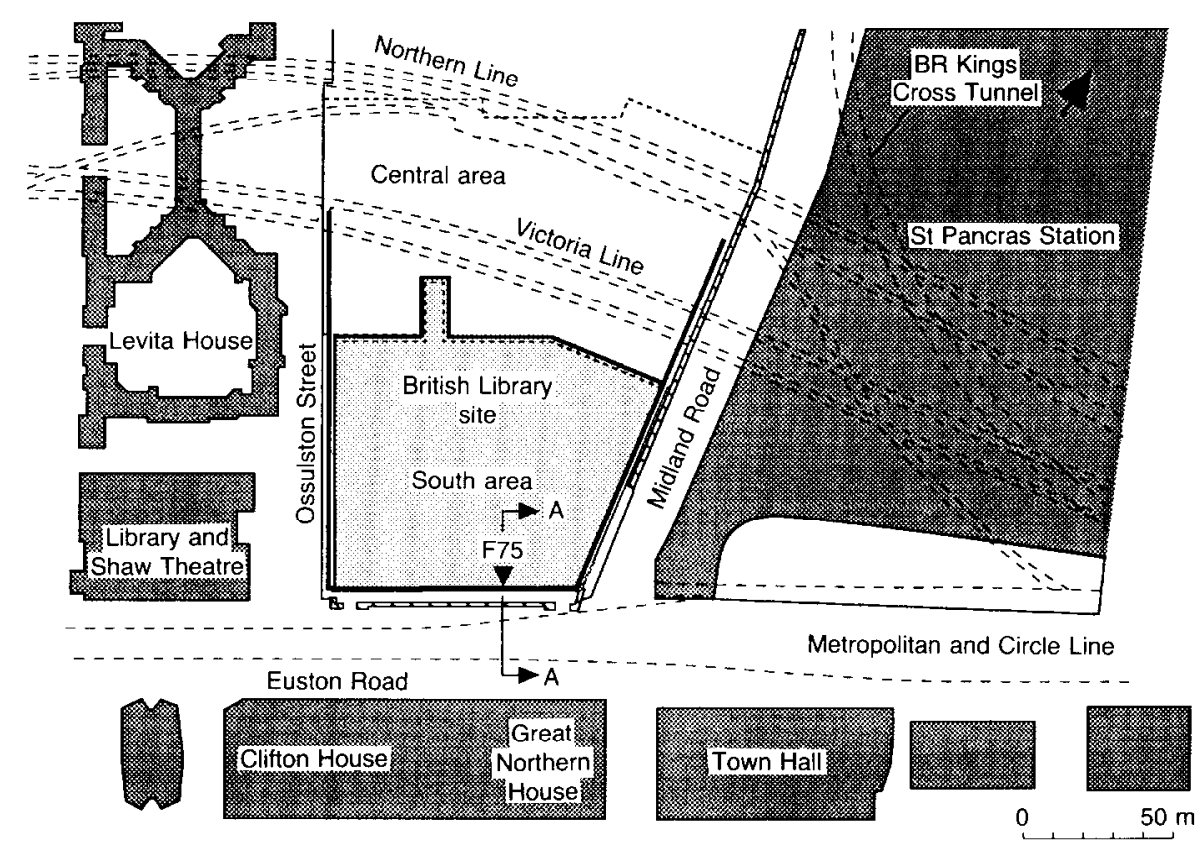

Fig. 9. Site plan for new British Library 


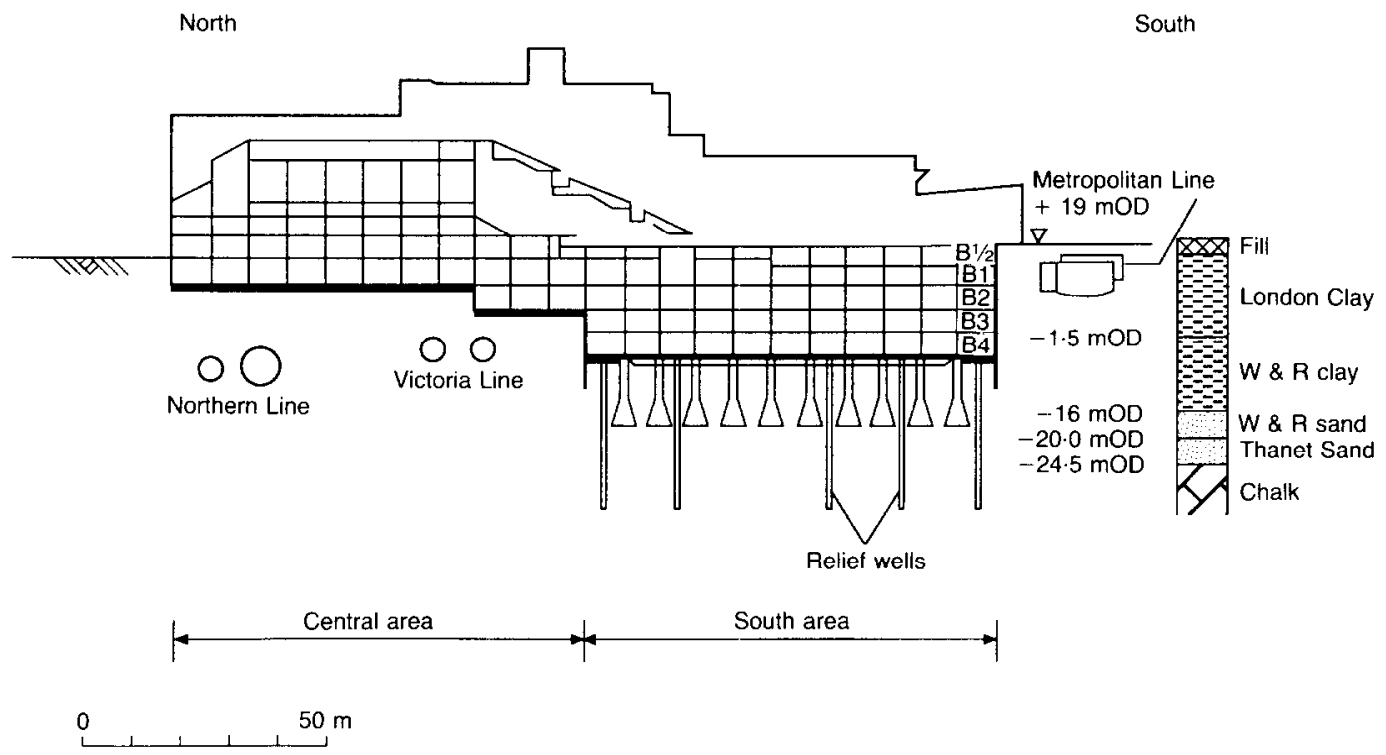

Fig. 10. North-south section through British Library

about $8 \mathrm{~mm}$ during the initial excavation, recovered $5 \mathrm{~mm}$, probably indicating some dissipation of negative pore pressures.

Figure 11 shows displacements recorded by inclinometers mounted in the walls at the end of that period. The best continuous record from an early stage is obtained from F75, located on the south wall as shown in Fig. 9. At a few points where instruments were available, ground movement caused by construction of the walls was too small to measure accurately, certainly not exceeding $5 \mathrm{~mm}$. However, it seemed that construction of the bored piling caused inward movement of the walls of up to about $10 \mathrm{~mm}$, equivalent to $1 \%$

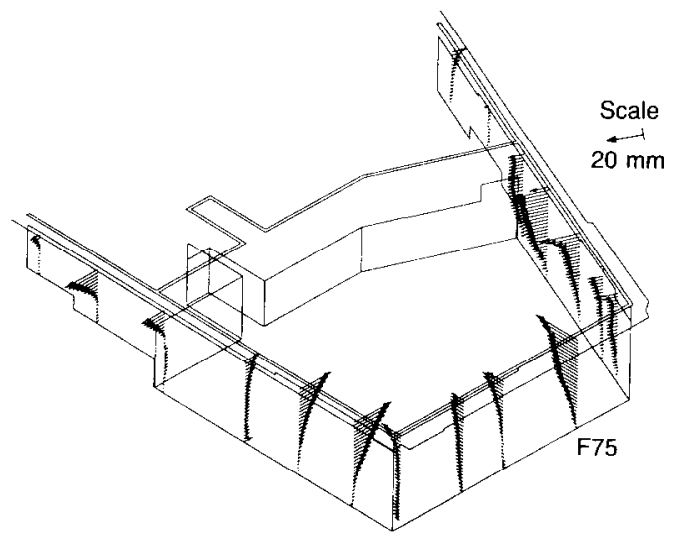

Fig. 11. Wall movements for initial $5 \mathrm{~m}$ excavation at British Library of the total area of the piles in plan. This figure is similar to the ground loss recorded in tunnelling operations.

\section{Excavation completed}

In the south area excavation generally proceeded floor by floor with each slab being cast before it was undermined. However, at the lowest basement level a very stringent method of construction was adopted. As shown in Fig. 12, a cruciform area was excavated and concreted first while most of the retaining walls were still supported by soil at this level. This area was then

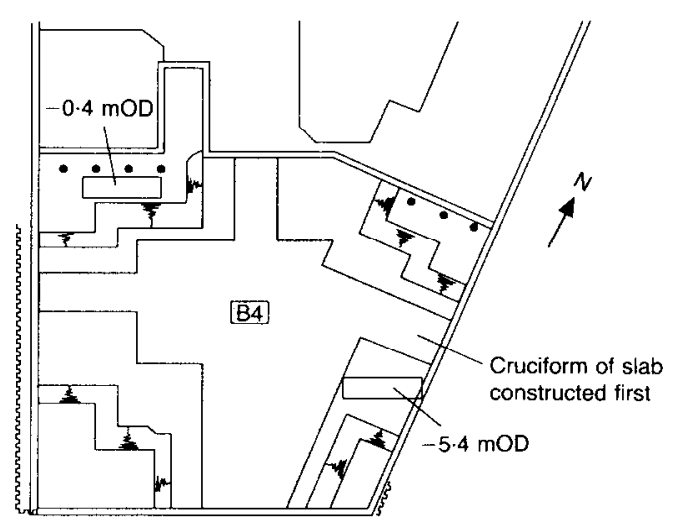

Fig. 12. Sequence of construction of B4 slab at British Library 


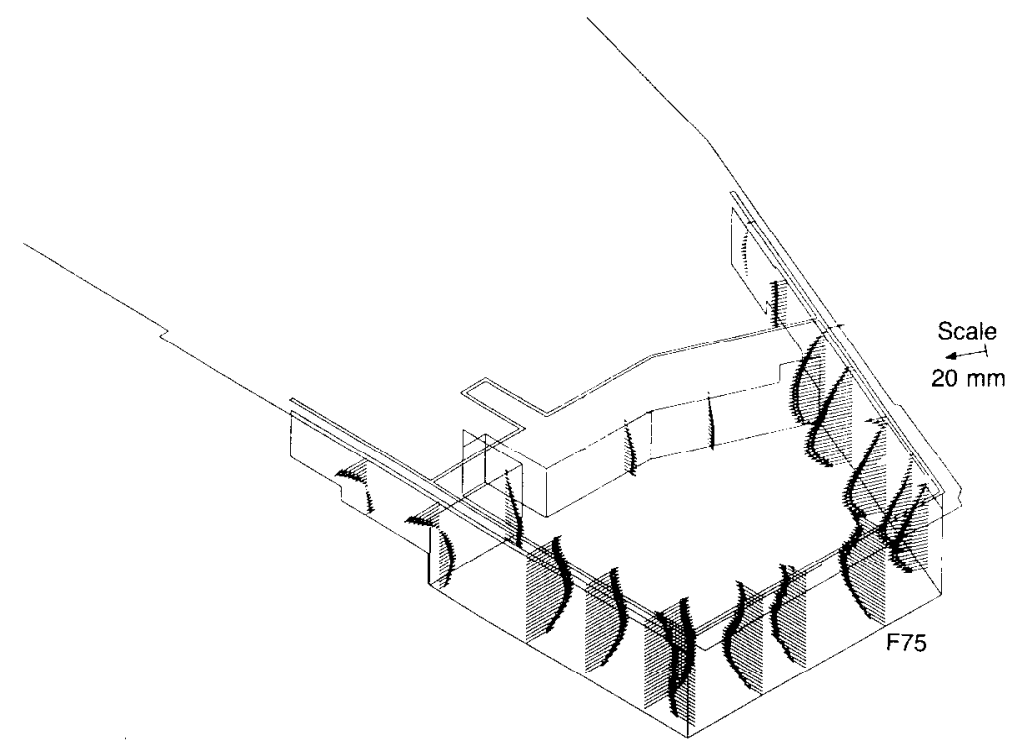

Fig. 13. Wall movements at end of construction at British Library

extended outwards in a piecemeal manner, replacing the soil berms by concrete as rapidly as possible. This procedure may have restricted movement significantly.

Figure 13 shows a bird's eye view of the site at the end of construction of the basement structure. The pattern of wall movement was fairly uniform, including $15-20 \mathrm{~mm}$ at the toe of the wall.

Measurements from inclinometers in boreholes were not very reliable and the results were adjusted to be consistent with the surface traversc survey. Fig. 14 shows that the picture obtained from two boreholes, inclinometer F75 in the wall and surveying inside the Metropolitan Line tunnel together form a consistent picture. Results from magnet extensometers inside the site (also shown in Fig. 14) consistently indicated rapid volumetric expansion of the clay after excavation. This appeared to be unrelated to availability of

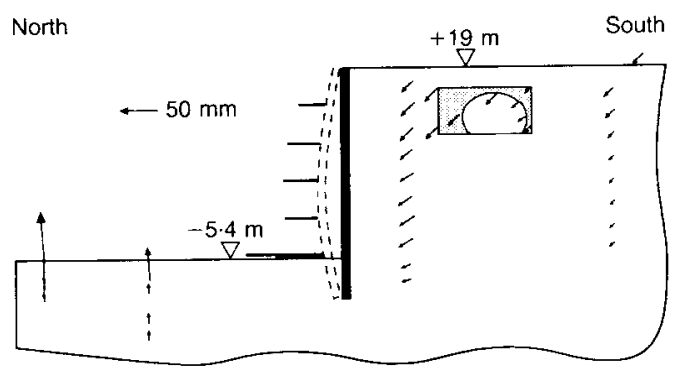

Fig. 14. Displacements on section AA (Fig. 9) at end of construction at British Library water and probably indicates a process of cavitation in the clay allowing undrained expansion.

Figure 15 shows results from inclinometers in the walls, firstly when the excavation had reached basement 3 (the B3 stage) and then at the end of construction at basement 4 . For back-analysis, the B3 stage may be more helpful because the excavation is almost entirely in London Clay at that stage and the rather complicated and restrictive construction sequence used at $\mathrm{B} 4$ is avoided. Inclinometer F75, which was commissioned before many of the others, recorded the biggest movements and it is likely that this is the most reliable indicator of overall movement.

\section{Computation of displacements}

Various computations of movement were carried out before and after construction. In the work reported here the main steps of the computations have been

(a) initial undrained excavation to about $5 \mathrm{~m}$ depth

(b) enforced loss of ground of $1 \%$ of the plan area of the piles, together with recovery to a fully drained state

(c) undrained excavation in stages for the remainder of the basement

(d) recovery to fully drained state.

The drainage in stage (b) corresponds to a twoyear delay on the site (1982-1984) during which the Metropolitan Line tunnel was observed to recover some of the settlement that had pre- 


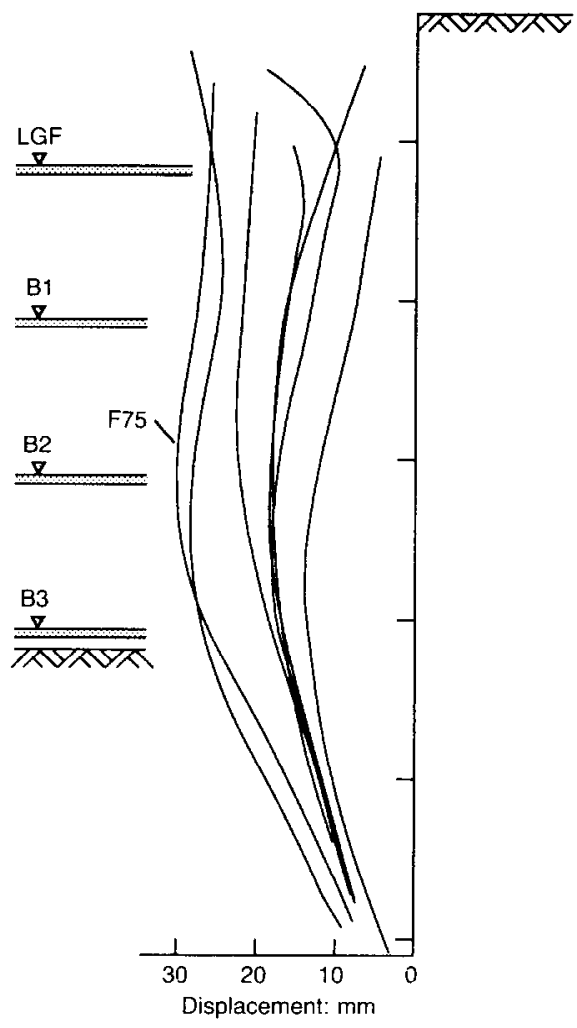

(a)

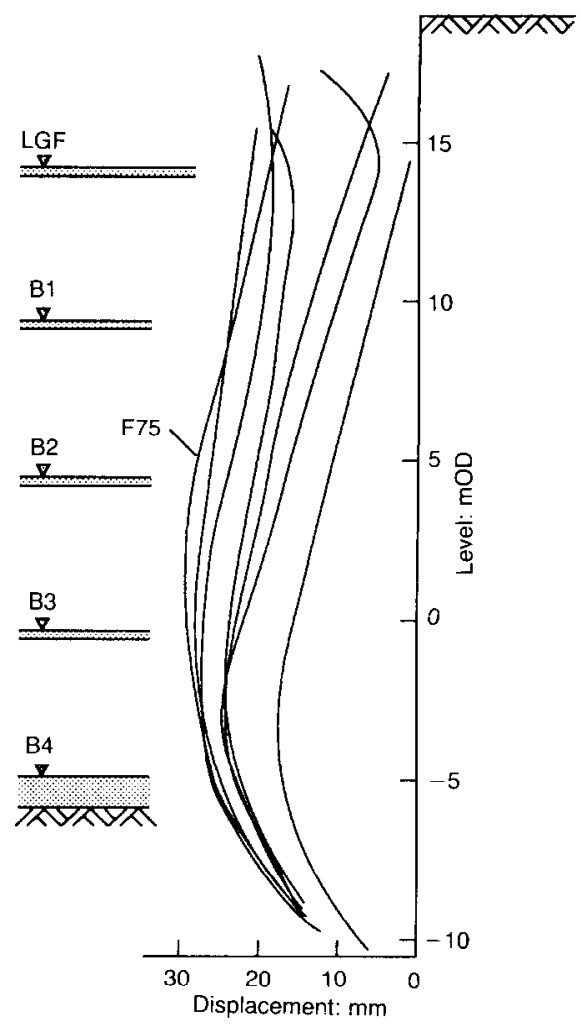

(b)

Fig. 15. Wall displacements at British Library: (a) at excavation to B3; (b) at end of construction

viously occurred. Movement computed in stage (d) was governed by assumptions about the creep properties of the concrete floor slabs and is not discussed here. The stiffnesses of the floor-struts were calculated assuming the Young's modulus of concrete to be $20 \mathrm{kN} / \mathrm{mm}^{2}$, with allowance for the presence of openings in the slabs.

Figure 16 shows the results of linear elastic finite element runs characterizing the undrained Young's modulus $E_{\mathrm{u}}$ by its ratio with the undrained shear strength $c_{\mathrm{u}}$. The value $E_{\mathrm{u}} / c_{\mathrm{u}}=$ 500 agrees closely with the stiffness profile derived from observations at Britannic House and used by Ward \& Burland (1973) in design of the Houses of Parliament underground car-park. So the computed displacements shown by the solid lines in Fig. 16 were available during the design of the basement, but there was some uncertainty about the justification of extrapolating results from one excavation to another larger one on the basis of linear behaviour. The measurements have shown that this would, in fact, have given a reasonable prediction of wall movement, especially since the upper end of the range of measurements probably gives a more reliable picture of the actual movements.

At the time British Library was designed there was concern that stifnesses of the order shown in Fig. 16 were not measured in laboratory tests on samples of the soil. It was fashionable in the $1970 \mathrm{~s}$ to conclude that samples obtained from boreholes were so badly disturbed that they revealed nothing useful about stiffness. There was a little evidence to suggest that the reason for this might be that laboratory tests were failing to measure stiffness in the range of very small strains which are relevant around deep excavations. Thinking it was important to investigate this, Simpson, O'Riordan \& Croft (1979) developed a model of soil behaviour that could be used in finite element analyses and which had the features shown in Fig. 17. In particular, at very small strains (as shown in the inset) it was assumed that its stiffness was ten times greater than values measured in laboratory tests. This behaviour was achieved by the use of a kinematic yield surface represented in strain space. Laboratory tests measuring very small strains were not available at 


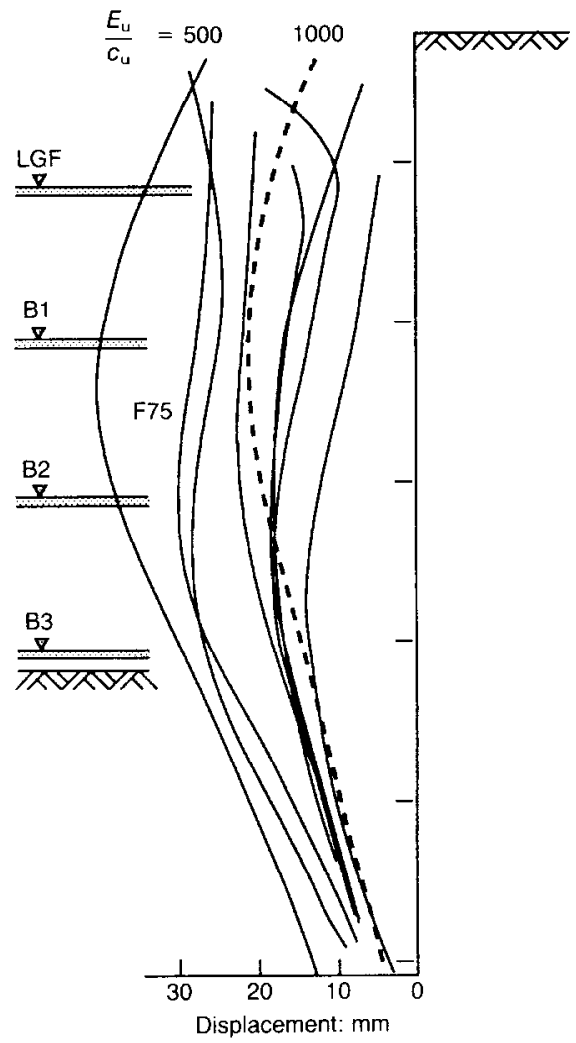

(a)

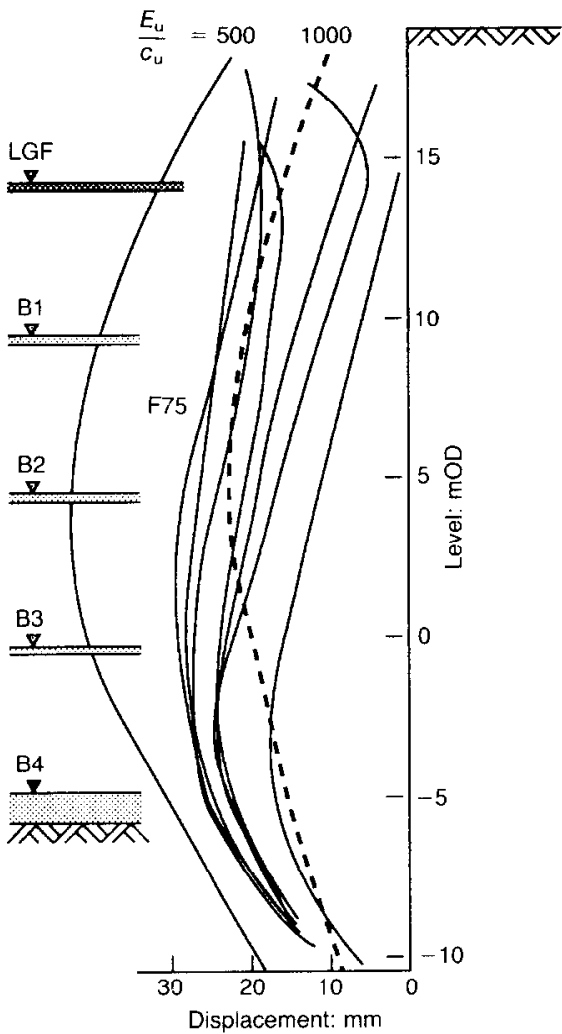

(b)

Fig. 16. Measured wall displacement at British Library compared with results of elastic finite element analysis

that time, so the details of the model were somewhat arbitrary; the intention was to allow a stress change of about $10 \%$ of in situ stress with very little strain. Besides displaying the features shown in Fig. 17, it was assumed throughout that stiffness was proportional to $\left(s+c^{\prime} \cot \phi^{\prime}\right)$, in which $s=\left(\sigma_{1}{ }^{\prime}+\sigma_{2}{ }^{\prime}\right) / 2$. The model was checked in a back analysis of the excavation at the Houses of Parliament and it predicted both the magnitude and pattern of ground movements quite well.

The model was developed to check that the ground movements at British Library were not underestimated in design. In the event it has proved to be much too soft and the computed wall movements were actually about double those that were measured. In the results shown in Fig. 18, standard allowances were incorporated for long-term shrinkage and creep of the floor slabs and this contributed considerable extra movements - the difference between the shortterm and long-term curves. In the event virtually none of this has taken place in almost five years since construction.
In this work the value adopted for the coefficient of earth pressure at rest $K_{0}$ was $1 \cdot 8$, determined largely on the basis of pressuremeter tests (Simpson et al. 1981). This was higher than could be calculated on the basis of the geological history of the site, allowing for the effects of reduced water pressures due to groundwater lowering in the underlying aquifer. The analysis has therefore been repeated using the same stressstrain model with $K_{0}=1 \cdot 4$, but this made little difference to the results. Burland, Simpson \& St John (1979) argued that an assumption of axial symmetry is more appropriate to computations for square excavations than is plane strain and that in some cases this significantly affects the results. However, for this problem it is found in both linear and non-linear analyses that this effect is minimal, perhaps because the depth to a relatively rigid stratum is small compared with the plan dimensions of the excavation.

\section{SOIL BEHAVES LIKE BRICKS ON STRINGS}

The model described above was formulated about 15 years ago; since then understanding of 


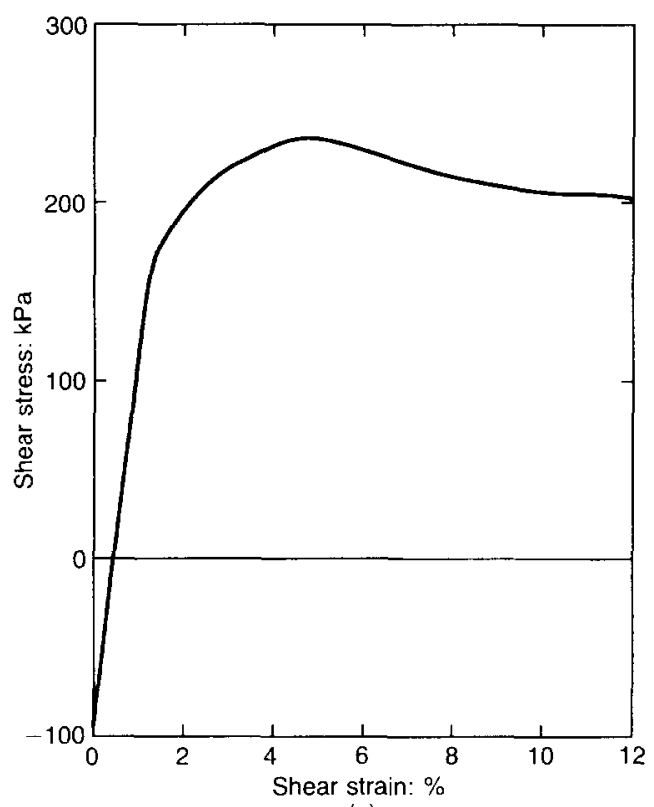

(a)

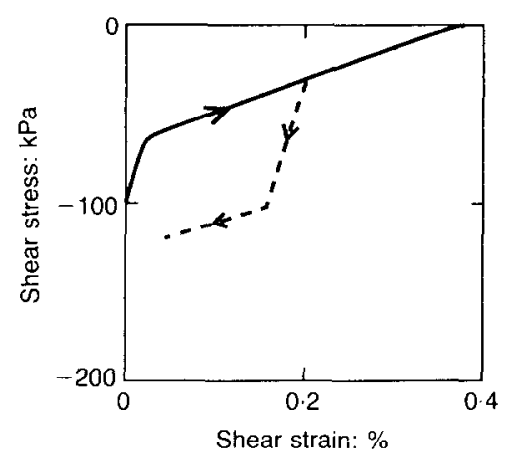

(b)

Fig. 17. Features of London Clay model published by Simpson et al. (1979)

the stiffness of soils at small strains has developed considerably and new models and numerical procedures have been proposed by various workers. Mroz et al. (1981) used the concept of multiple kinematic yield surfaces in stress space, together with a degradation parameter to represent cyclic loading. Jardine et al. (1985) and others at Imperial College, London have developed a more empirical model to fit features of undrained behaviour of London Clay, and Al Tabbaa (1987) and Stallebrass (1990) have extended the Cam clay type of soil model.

Much recent attention has centred around the type of diagram shown in Fig. 19(a), often referred to as the S-shaped curve, which shows how soil stiffness is high when the strains are small but reduces as straining proceeds. Strain is usually plotted on a $\log$ scale for this purpose. This representation of soil behaviour has been in use in soil dynamics for many years (e.g. Seed \& Idriss, 1970), and its application in static behaviour was a particular feature of the 'lenth European Conference on Soil Mechanics and Foundation Engineering, held in Florence in 1991. During this conference the author was questioned about methods of modelling the behaviour of stiff clay, particularly Gault Clay, at small strains and this conversation led to the development of the ideas described here.

It is a common assumption that strains can be divided into those which are elastic and those which are plastic. Generally, elastic components of strain cause changes of stress; plastic components cause no change of stress. As a material yields and becomes less stiff, its elastic stiffness does not diminish as a function of strain. Evidence of this type of behaviour can be seen in the unload-reload loops used in many geotechnical tests.

In Fig. 19(b), the S-shaped curve is treated as a graph showing what proportion of the soil is behaving elastically at each stage as strains develop. At very small strains the soil is $100 \%$ elastic, but as strains become larger, more of the soil behaves plastically and the overall stiffness reduces. The elastic stiffness could be roughly constant if a decreasing proportion of the soil behaves elastically as straining proceeds. The elastic 'proportion' of the soil might, for example, represent the proportion of the contacts between soil particles which are still intact and have not started to slide.

Richardson (1988) carried out a set of triaxial tests on reconstituted London Clay, concentrating on the accurate measurement of small strains. Referring to Fig. 20(a), he consolidated specimens to point $\mathrm{A}$ in $(p, q)$ space, then studied stress path OX, for which $p$ is constant at $200 \mathrm{kPa}$. He took specimens from $A$ to $O X$ by various routes, such as $\mathrm{AOX},(\mathrm{AO}) \mathrm{BOX},(\mathrm{AO}) \mathrm{COX}$ and $(\mathrm{AO}) \mathrm{DOX}$. In each case he studied the stiffness of the specimen for the final path $O X$.

Plotting tangent shear stiffness against log (shear strain), he obtained the S-shaped curves shown in Fig. 20(b). He found that the highest stiffness along OX occurred for path DOX, which included a $180^{\circ}$ reversal in the stress path at $\mathrm{O}$. $A O X$ and $C O X$ with $90^{\circ}$ turns at $O$ came next and $B O X$, which passed straight through $O$, gave the lowest stiffness for path $O X$. The soil readily continues straining in the direction in which it was previously moving (BOX), but is much stiffer if it is made to change direction, especially for $180^{\circ}$ turns such as path DOX. 


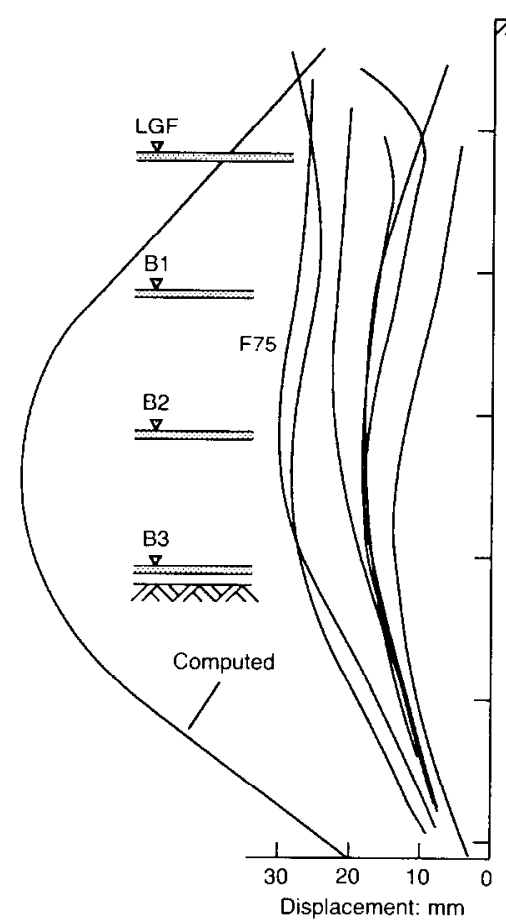

(a)

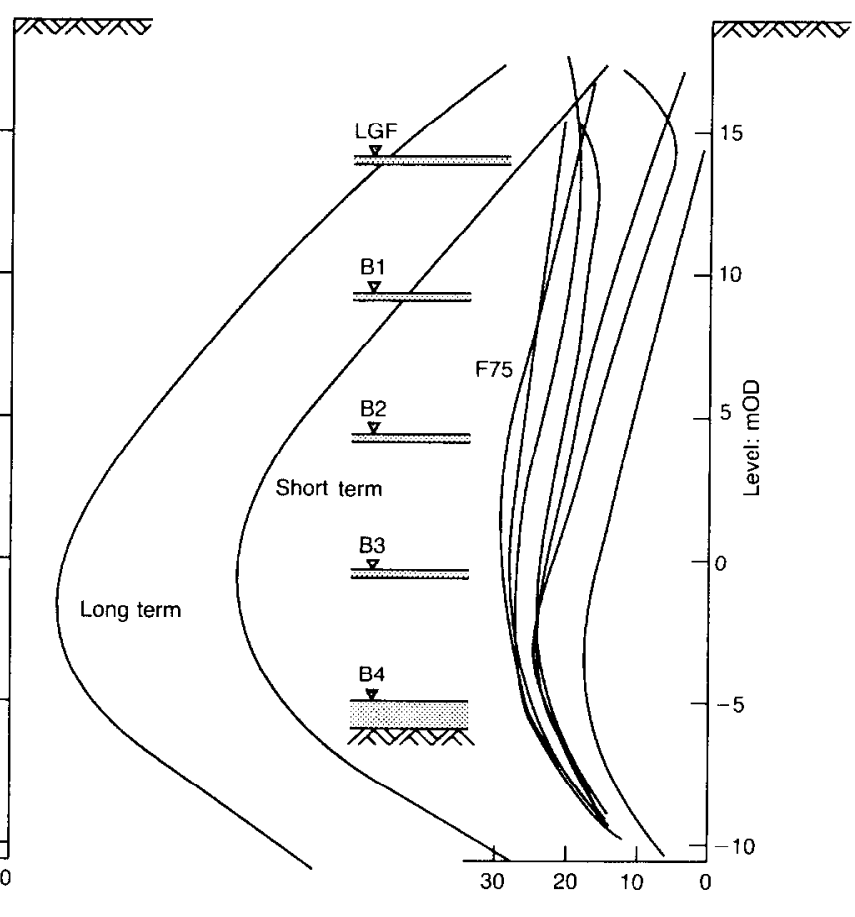

(b)

Fig. 18. Measured wall displacement at British Library compared with finite elements using the 1979 model

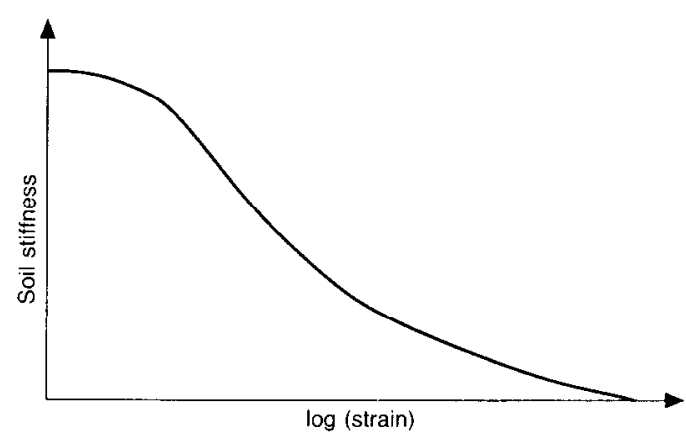

(a)

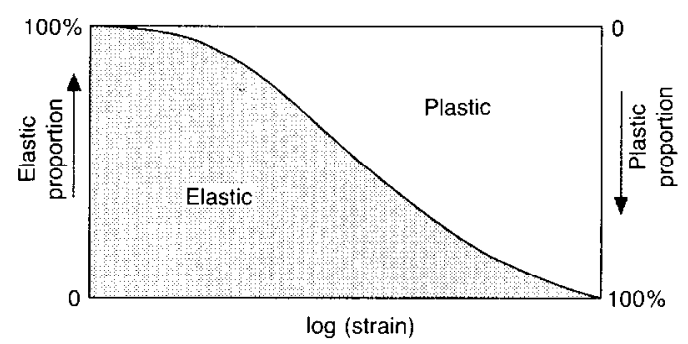

(b)

Figure 21 shows results obtained in similar tests by Stallebrass (1990), this time on kaolin. Superimposed on to $(p, q)$ stress axes, this plot shows strain vectors, indicating the ratios of the normal and shear components of incremental strain as the test proceeded from $O$ towards $X$. When the stress path changes direction abruptly at point $O$ the soil tends to continue straining in the direction in which it was previously going.

\section{An analogue}

A physical analogue bears a striking resemblance to this type of behaviour. Imagine a man walking around a room and pulling behind him a series of bricks, each on a separate string. Some possible paths for the man and the strings are shown in Fig. 22. If he walks continuously in one direction the bricks line up behind him and follow him (Fig. 22(a)). If he turns back (Fig. 22(b)) the bricks initially do not move; then the ones on shorter strings start to move, gradually followed by the longer strings (Fig. 22(c)). If he turns through $90^{\circ}$, the bricks initially keep moving in their previous direction but gradually swing round behind him (Fig. 22(d)). The simi- 
larity to soil behaviour is obvious, but it is less clear how the analogue could be useful. What would the bricks and strings represent and what are the axes of the room?

Engineers with a background in plasticity might see in this analogue plastic yield surfaces with axes of stress space. However, the equivalence which has been found most useful is to regard the room as strain space. The comment from Burland's thesis is relevant here: 'Stress is a philosophical concept-deformation is the physical reality'. In this context deformation means particles of soil distorting and then moving relative to one another. This is represented on average by the strain in the soil.

The analogue is found to be remarkably useful if the man is taken to represent the point in strain space of a soil element and each brick represents a proportion of the element. Movement of a brick represents plastic strain, and elastic strain is given by the difference between the movement of the man and the sum of the movements of the bricks, each weighted by the proportion of the soil it represents. In this view, pure elastic behaviour only occurs on the rare occasions when no bricks are moving, i.e. immediately after a reversal of the strain path. It is assumed that only elastic strains cause changes of stress.

The S-shaped curve could be modelled in a stepwise fashion as shown in Fig. 23. At very small strains, the material is completely elastic; in the analogue, none of the bricks is moving. As straining proceeds one of the bricks starts to move, plastic strain begins and there is a drop in

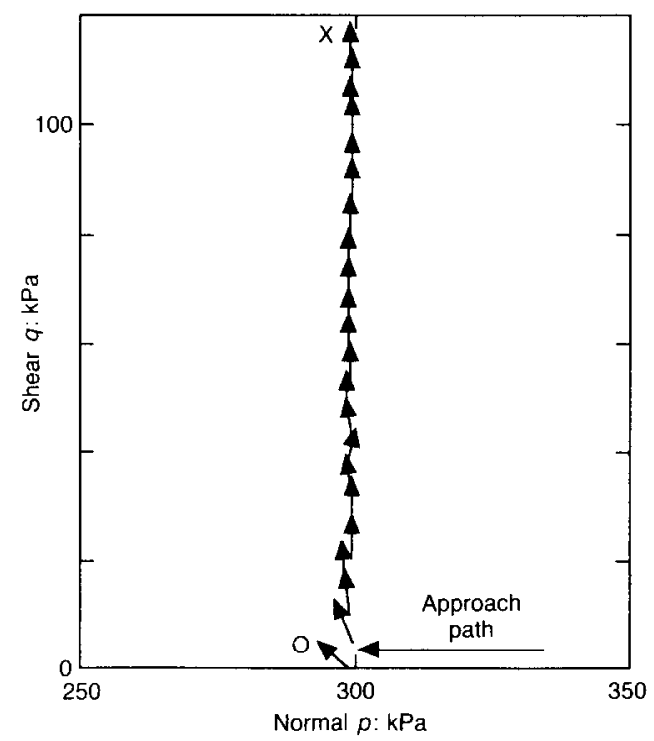

Fig. 21. Strain vectors observed by Stallebrass (1990)

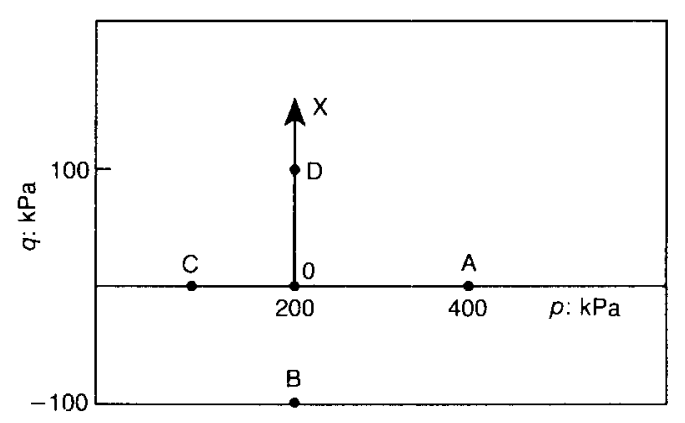

(a)

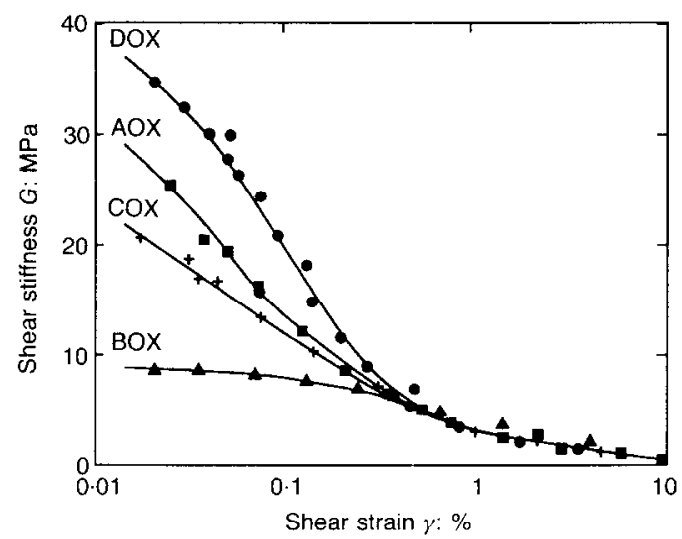

(b)

Fig. 20. Results obtained by Richardson (1988) for stress path OX: (a) stress paths; (b) S-shaped curves showing tangent shear stiffness

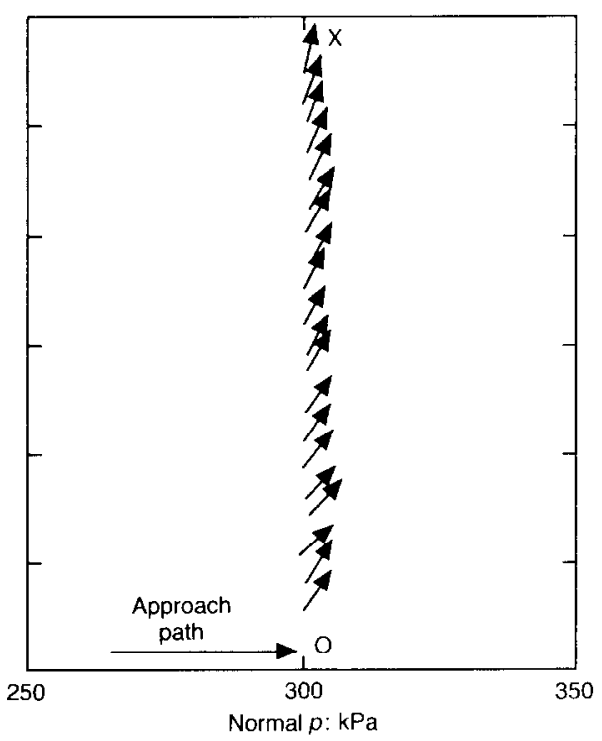




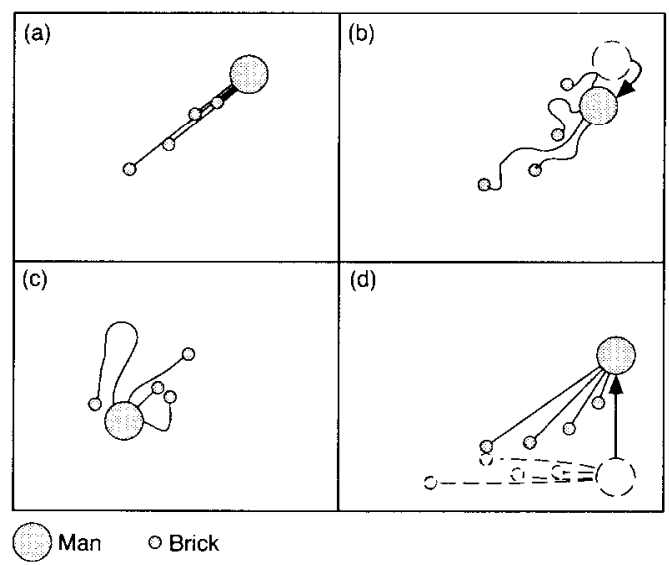

Fig. 22. A man pulling bricks attached to him by strings

the overall stiffness of the soil. At a larger strain, another brick starts to move; there is more plasticity and a further drop in stiffness, and so on. The length to each step is a strain, represented by the length of a string in the analogue. The height of the step indicates the proportion of material represented by each of the bricks.

The model has been developed in plane strain for which volumetric strain and shear strain are appropriate axes-the sides of the room. Considering first principal strains $\left(\varepsilon_{1}, \varepsilon_{2}\right)$ in fixed directions, a plane strain model for soil which is structurally isotropic should treat each direction equally and the axis system could therefore be $\left(\varepsilon_{1}\right.$,
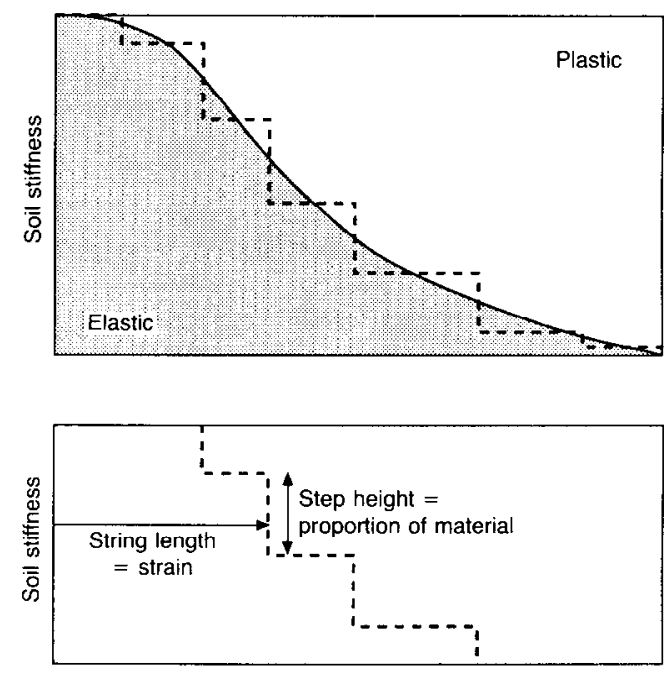

$\log$ (strain)

Fig. 23. The S-shaped curve represented in stepwise fashion $\left.\varepsilon_{2}\right)$. It is more convenient to use $(v, \gamma)$, where $v$ is volumetric strain and $\gamma$ is the diameter of the Mohr's circle of strain. In coordinate axes $(x, y), \gamma$ is equal to $\left(\left(\varepsilon_{x}-\varepsilon_{y}\right)^{2}+\gamma_{x y}{ }^{2}\right)^{1 / 2}$. Since this has the appearance of the vector sum of two orthogonal components, it is reasonable to adopt $\left(v, \varepsilon_{x}-\varepsilon_{y}\right.$, $\left.\gamma_{x y}\right)$ as axes. The validity of this choice will be reviewed later.

The concept is easily represented in a small computer program into which other features of established theory about soil behaviour can be incorporated. In the work described in this Paper, ten 'bricks' have been used, representing the Sshaped curve in ten steps. A larger number could be used without changing the program if greater accuracy were needed. The Paper will illustrate one way in which this concept can be built into a more complete soil model, but there could be many others. The most significant feature is the basic concept that the soil behaves rather like the bricks on strings. Although the concept has so far only been used in plane strain, the Author considers that it could readily be extended for use in a full three-dimensional model.

The model was first tested using plane strain stress paths equivalent to those of Richardson (1988). In this Paper, stress plots in plane strain use mean stress $s=\left(\sigma_{x}+\sigma_{y}\right) / 2$ and shear stress $t=\left(\sigma_{y}-\sigma_{x}\right) / 2 ; t$ is plotted at double the scale of $s$ so that the curves resemble the more familiar results of triaxial tests plotted in $(p, q)$ space. Using Richardson's data, string lengths and material proportions were chosen to fit path DOX of Fig. 20 in a stepwise fashion. With those data and the brick concept, the program predicted the stiffness of path DOX and the other paths, as shown in Fig. 24. Paths AOX and COX appear almost identical in plane strain and BOX has a much lower stiffness. Plotting tangent stiffness, the curves appear rather bumpy, but this would not be noticeable if secant stiffness were plotted, or if the model were used in a finite element program.

Figure 24 shows that the brick concept achieves its main purpose of modelling the effects of changes in stress paths and reproducing the Sshaped curves which represent the small strain behaviour of clays. However, it has also been found to have a much wider potential.

\section{Additional assumptions}

The brick concept could be used in conjunction with a variety of additional equations describing other features of the soil behaviour. A series of assumptions taken from critical state soil mechanics are used here to complete the model. The values of parameters used in this Paper for all computations involving London Clay, including 
Fig. 24, are shown in Table 1 and are discussed as they are introduced below. Since their initial derivation from the work of Richardson (1988), these values have been refined in the light of other field and laboratory data.

Elastic volumetric stiffness. This is assumed to be proportional to current mean normal stress. Denoting elastic strains by the subscript $\mathrm{e}$

$$
\delta s \propto s \delta v_{\mathbf{e}}
$$

The constant of proportionality is similar to $\lambda$ and $\kappa$ used in the Cam clay models. However, it relates only to very small (ideally elastic) strains and will be denoted by the preceding letter in the Greek alphabet, $t$, which seems an appropriate constant to represent very small strain behaviour. (The parameters $\lambda, \kappa$ and $t$ used in this Paper are equivalent to $\lambda^{*}$ and $\kappa^{*}$ as discussed by Houlsby $\&$ Wroth (1991), since they are defined in terms of volumetric strain $v$ rather than voids ratio.) Thus equation (1) becomes

$$
\delta s=s \delta v_{\mathrm{e}} / l
$$

The value $1=0.0041$ has been used here. Initially a value of 0.0032 was adopted and published by Simpson (1993), but the derivation had not allowed correctly for the effect of the parameter $\beta$, described below, in Richardson's and Viggiani's laboratory tests. Viggiani (1992) reports the results of small strain tests on triaxial specimens equipped with Hall effect transducers and bender elements. She proposes that the shear modulus at very small strain $G_{\max }$ is proportional to $p^{0.83}$, not $s^{1}$ as presently assumed in the model. However, line AA on Fig. 25(a) lies close to Viggiani's data for normally consolidated clay and corrcsponds to $G_{\max } / p=146$. Assuming that this

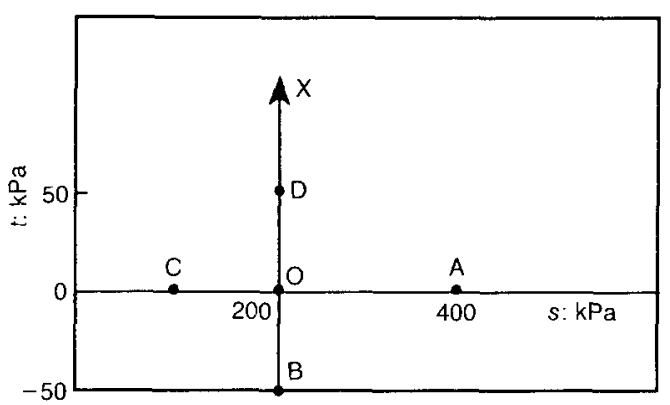

(a)

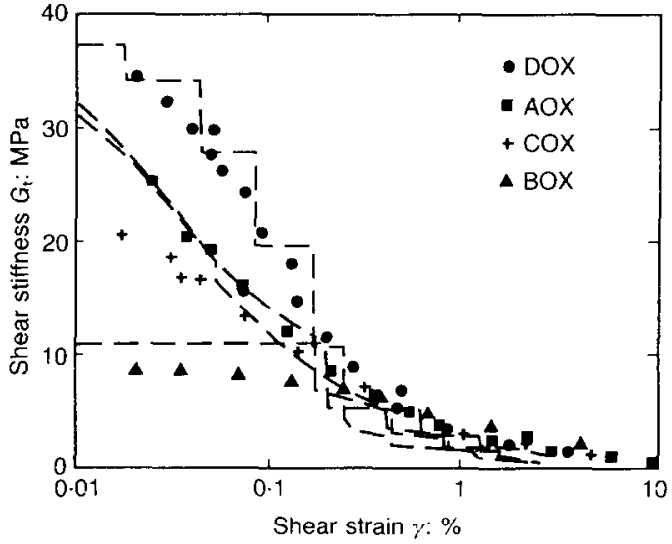

(b)

Fig. 24. BRICK model predictions for Richardson's (1988) tests

is equivalent to $G_{\max } / s=146$, it follows that $(1-2 v) / \imath=146$, from which $\iota=0.0041$ for $v=0 \cdot 2$.

Elastic shear stiffness. This is derived from elastic volumetric stiffness assuming a constant

\begin{tabular}{|c|c|c|c|c|c|c|}
\hline \multirow[t]{2}{*}{ String } & \multicolumn{3}{|c|}{ London Clay } & \multicolumn{3}{|c|}{ Singapore Clay } \\
\hline & $\begin{array}{l}\text { String } \\
\text { length }\end{array}$ & $G_{v} / G_{\max }$ & $\begin{array}{l}\text { Proportion } \\
\text { of material }\end{array}$ & $\begin{array}{l}\text { String } \\
\text { length }\end{array}$ & $G_{v} / G_{\max }$ & $\begin{array}{l}\text { Proportion } \\
\text { of material }\end{array}$ \\
\hline 1 & 0.000083 & 0.92 & 0.08 & 0.00008 & 0.92 & 0.08 \\
\hline 2 & 0.00021 & 0.75 & $0 \cdot 17$ & 0.0002 & 0.75 & $0 \cdot 17$ \\
\hline 3 & 0.00041 & 0.53 & 0.22 & 0.0004 & 0.53 & 0.22 \\
\hline 4 & 0.00083 & $0 \cdot 29$ & $0 \cdot 24$ & 0.0008 & $0 \cdot 29$ & 0.24 \\
\hline 5 & 0.0022 & 0.13 & $0 \cdot 16$ & 0.002 & $0 \cdot 13$ & 0.16 \\
\hline 6 & 0.0041 & 0.075 & 0.055 & 0.004 & 0.075 & 0.055 \\
\hline 7 & 0.0082 & 0.044 & 0.031 & 0.008 & 0.044 & 0.031 \\
\hline 8 & 0.021 & 0.017 & 0.027 & 0.018 & 0.017 & 0.027 \\
\hline 9 & 0.041 & 0.0035 & 0.0135 & 0.036 & 0.0035 & 0.0135 \\
\hline \multirow[t]{2}{*}{10} & 0.08 & 0 & 0.0035 & 0.075 & 0 & 0.0035 \\
\hline & \multicolumn{3}{|c|}{$\begin{array}{c}\lambda=0.1 \quad \kappa=0.02 \quad \imath=0.0041 \\
\nu=0.2 \quad \beta=4 \\
\text { Implied } \phi_{\text {crit }}^{\prime}=22^{\circ}\end{array}$} & \multicolumn{3}{|c|}{$\begin{array}{c}\lambda=0 \cdot 1 \quad \kappa=0.04 \quad t=0.0032 \\
\nu=0 \cdot 2 \quad \beta=4 \\
\text { Implied } \phi_{\text {crit }}^{\prime}=26^{\circ}\end{array}$} \\
\hline
\end{tabular}

Table 1. Parameter values used for London Clay and Singapore marine clay 


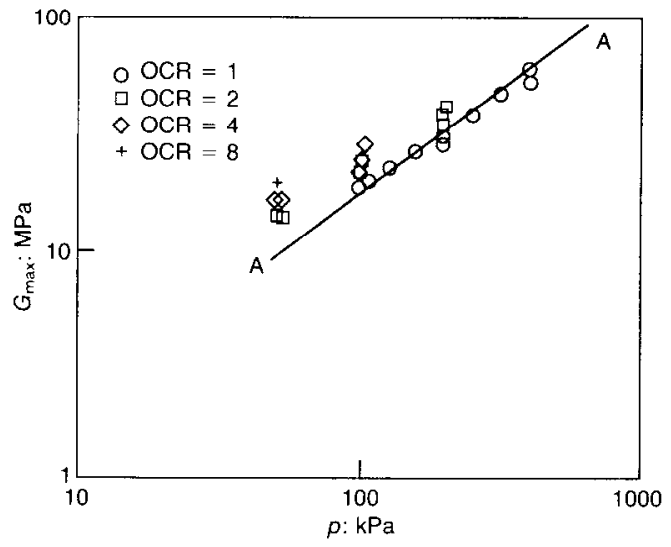

(a)

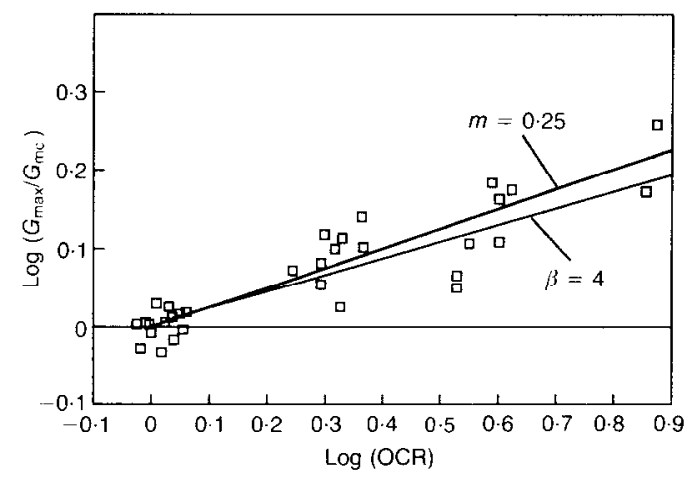

(b)

Fig. 25. BRICK predictions compared with test results of Viggiani (1992)

Poisson's ratio $v$. Thus, for plane strain

$$
\delta t=s \delta \gamma_{\mathrm{e}}(1-2 v) / l
$$

It is possible that Poisson's ratio for elastic strains should be varied as a function of stress state, but this has not been investigated and $v=0.2$ has been assumed.

Consolidation and swelling. When the normal stress on a frictional body is increased, its ability to strain elastically without slip is also increased. Hence it would be expected that as mean normal stress is increased the soil's capacity to strain elastically and so to accept further normal and shear stresses will be extended. This gives rise to the log-linear compression and swclling lincs which are often clearly displayed by soils and which are represented in Cam clay models by the parameters $\lambda$ and $\kappa$. In the present model it is assumed that during normal compression increase of mean normal stress makes available an additional capacity for elastic strain $\delta v_{\mathrm{c}}$ equal to $(l / \lambda) \delta v$. During unloading and reloading this is modified to $\delta v_{\mathrm{c}}=(l / \kappa) \delta v$, making the model display the normal $\lambda, \kappa$ behaviour typical of Cam clay, but modified by the brick effect when the stress-strain path is not straight. Additional capacity for elastic shear is also assumed, given by the equation $\delta \gamma_{\mathrm{c}}=(t / s) \delta v_{\mathrm{c}} /(1-2 v)$, which was chosen to ensure radial straight lines in $(s, t)$ stress space during isotropic normal consolidation.

The value $\lambda=0 \cdot 1$ was taken from Schofield $\&$ Wroth (1968), allowing for the definition used here in terms of volumetric strain; the value of $\kappa$ is discussed below.

\section{Results for normally consolidated soil}

Although the model was initially intended to represent overconsolidated clay, its predictions for normally consolidated soil are found to be of interest. The results to be shown here were computed using a constant set of parameters of the model and in each case the strains were specified as input to the computer program. The stresses and stiffnesses were computed for the specified strains.

Figure 26 shows strain and stress paths for undrained tests on normally consolidated clays. The computed results in Fig. 26(c) and (f) are remarkably similar to the measurements in Fig. 26(b) and (e). Furthermore, each computed result is found to fail at the same angle of shearing resistance, in this case $22^{\circ}$, although this is not explicitly a parameter of the model. Other draincd and undraincd stress paths all fail at the same angle of shearing resistance for the same set of material parameters.

The tendency to fail at a constant angle of shearing resistance can be explained by reference to Fig. 27. If the S-shaped curve is plotted using tangent shear modulus $G_{\mathrm{t}}$ and assuming stiffness proportional to mean stress $s$ then the area under the curve $A$ determines the stress ratio at failure and is therefore equal to $\sin \phi^{\prime}$. If the S-shaped curve in this form is constant, $\phi^{\prime}$ will be constant. This is easily shown for the case $s=$ constant

$$
\begin{aligned}
A & =\int\left(G_{\mathrm{t}} / s\right) \mathrm{d} \gamma \\
& =(1 / s) \int(\mathrm{d} t / \mathrm{d} \gamma) \mathrm{d} \gamma \\
& =t / s \\
& =\sin \phi^{\prime} \text { at failure }
\end{aligned}
$$

Hence, although the S-shaped curve is a description of stiffness, the area under the curve dictates the angle of shearing resistance.

For one-dimensional consolidation, the model always returns to a unique line in stress space even when disturbed from it by other excursions, 


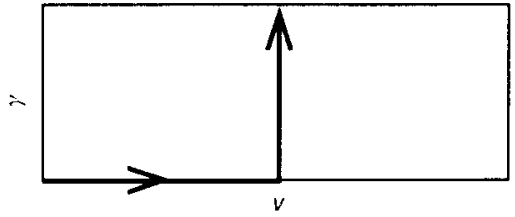

(a)

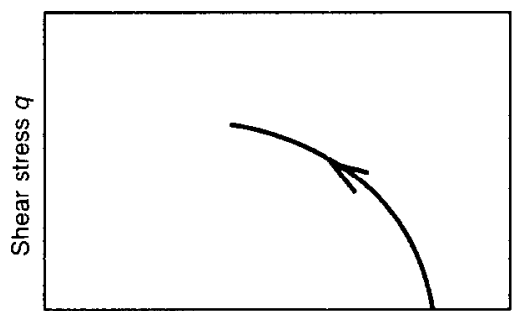

Normal stress: $p$

(b)

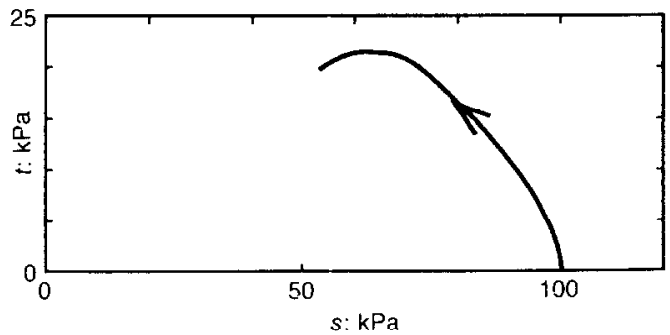

(c)

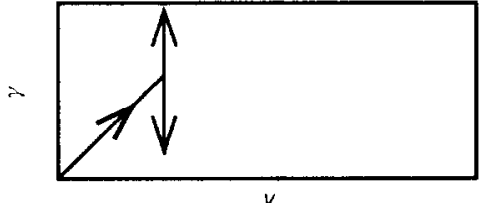

(d)
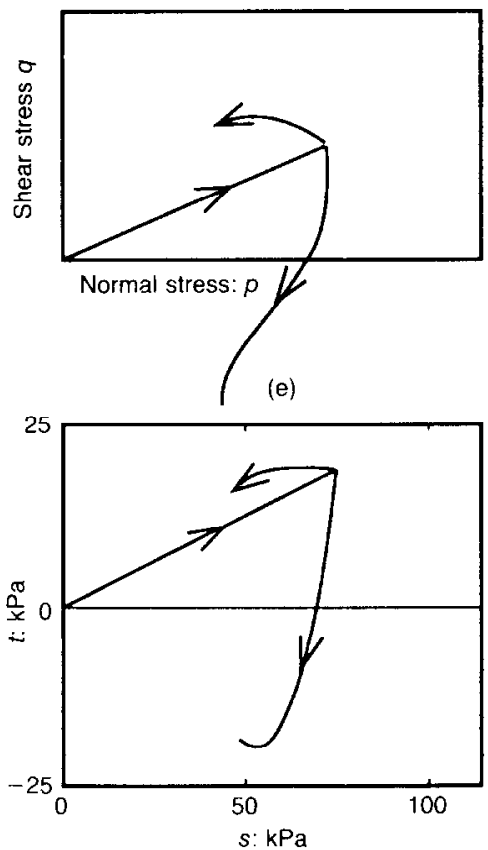

(f)

Fig. 26. Undrained tests on normally consolidated clays: (a) strain path for plane strain; (b) triaxial tests on kaolin (Loudon, 1967); (c) BRICK result for London Clay in plane strain; (d) strain paths for one-dimensional consolidation in plane strain; (e) triaxial tests on kaolin (Balasubramaniam, 1967); and (f) BRICK result

as shown in Fig. 28. The gradient of this line determines $K_{0}$ during normal consolidation. The model does not have $K_{0}$ as a parameter, but during one-dimensional normal consolidation the positions of the strain point and bricks lie on a straight line inclined at $45^{\circ}$ to the $v$ and $\gamma$ axes as shown in Fig. 22(a). This implies that the elastic shear strain which will govern shear stress will be $\cos 45^{\circ}$ times that developed during failure in pure shear. Hence the angle of friction mobilized in one-dimensional consolidation will be given by $\sin \phi_{\mathrm{mob}}^{\prime}=\sin \phi^{\prime} / \sqrt{ } 2$, which leads to the equation

$$
\begin{aligned}
K_{0} & =\left(1-\sin \phi^{\prime} / \sqrt{ } 2\right) /\left(1+\sin \phi^{\prime} / \sqrt{ } 2\right) \\
& =\left(\sqrt{ } 2-\sin \phi^{\prime}\right) /\left(\sqrt{ } 2+\sin \phi^{\prime}\right)
\end{aligned}
$$

In Fig. 29 this equation is compared with the equation of Jaky (1944): $K_{0}=1-\sin \phi^{\prime}$. Brooker \& Ireland (1965) proposed a modified form of

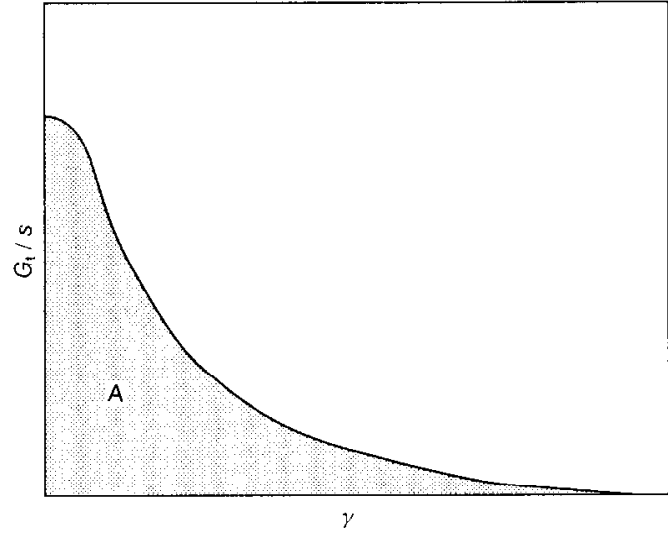

Fig. 27. The S-shaped curve plotted as normalized tangent shear modulus against shear strain 


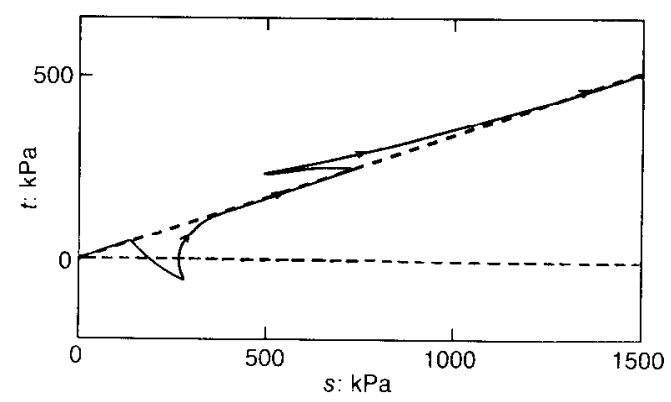

Fig. 28. Stress path predicted for one-dimensional consolidation with other excursions

Jaky's equation for clays: $K_{0}=0.95-\sin \phi^{\prime}$, and Bolton (1991) has proposed another equation based on the study of sands: $K_{0}=(1-\sin$ $\left.\phi_{\mathrm{mob}}^{\prime}\right) /\left(1+\sin \phi_{\mathrm{mob}}^{\prime}\right)$, in which $\phi_{\mathrm{mob}}^{\prime}=\phi^{\prime}-11 \cdot 5^{\circ}$. Both these modified equations are also shown in Fig. 29. Equation (4) agrees very well with Brooker \& Ireland's equation for the range of $\phi^{\prime}$ appropriate to clays $\left(20^{\circ}-30^{\circ}\right)$ and with Bolton's equation for that appropriate to sands $\left(30^{\circ}-40^{\circ}\right)$. It lies fairly close to Jaky's equation for the full range of $\phi^{\prime}$. This close agreement between the prediction of the BRICK model and measured values for $K_{0}$ gives strong support to the choice of axes in which to usc the model as discussed earlier.

\section{Overconsolidated clays}

Houlsby \& Wroth (1991), Viggiani (1992) and others have suggested that stiffness varies linearly with logarithm of overconsolidation ratio. The formulation adopted here assumes that stiffness varies linearly with $\left(v-v_{0}-\lambda \ln \left(s / s_{0}\right)\right)$, which is similar in concept to the term $e_{\lambda}=e+\lambda \ln (s)$ used by Wroth (1971). The parameters $v_{0}$ and $s_{0}$ indicate the initial state relative to which consoli-

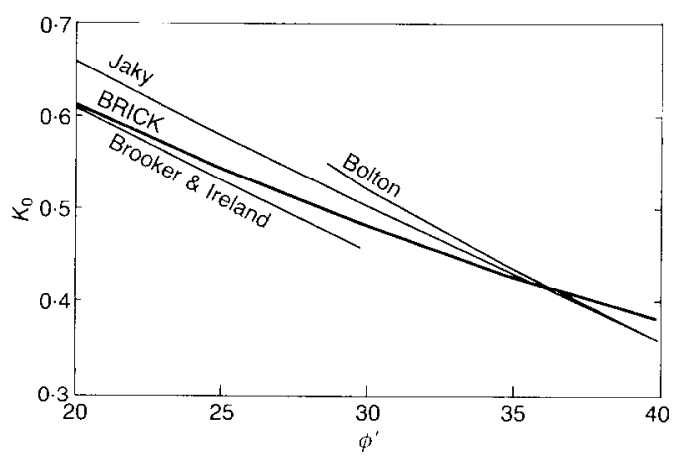

Fig. 29. BRICK prediction for $\boldsymbol{K}_{0}$ of normally consolidated soil compared with other theories dation is to be measured; in applications to date it has been taken to represent a slurry with $s_{0}=$ $2 \mathrm{kPa}$ and $v_{0}=0$, an arbitrary origin of volumetric strain. Stiffness is multiplied by $(1+$ $\left.\beta\left(v-v_{0}-\lambda \ln \left(s / s_{0}\right)\right)\right)$, where $\beta$ is a material constant. If there were no BRICK effect, the term $\left(v \quad v_{0}-\lambda \ln \left(s / s_{0}\right)\right)$ would reduce to $(\lambda-\kappa) \ln (\mathrm{OCR})$.

Figure $25(\mathrm{~b})$ shows Viggiani's measured values of the ratio of $G_{\max }$ to its value for normally consolidated clay $G_{\mathrm{nc}}$. Using the other parameter values listed in Table 1 for London Clay, volumetric strains $v$ have been derived from the BRICK model for a load-unload test (shown in Fig. 30) in order to calculate $\left(1+\beta\left(v-v_{0}-\lambda \ln \left(s / s_{0}\right)\right)\right)$. It can be seen that the assumption that $G_{\max } / G_{\mathrm{nc}}$ is equal to this function fits Viggiani's data very well if $\beta=4$.

Since the area under the S-shaped curve determines $\sin \phi^{\prime}$, a parameter such as $\beta$ which leads to increased stiffness also causes an increase in $\sin \phi^{\prime}$. Thus the model automatically gives a higher angle of shearing resistance to an ovcrconsolidated clay than to the same clay in its normally consolidated state. This is also consistent with the ohservation of Stroud (1971) that for Leighton Buzzard sand peak $\sin \phi^{\prime}$ and $e_{\lambda}$ are linearly related.

Houlsby \& Wroth (1991) and Viggiani (1992) favour the assumption that stiffness is proportional to $p^{n-1} p_{\mathrm{c}}{ }^{\mathrm{n}}$, where $p_{\mathrm{c}}$ is the preconsolidation pressure. Viggiani proposes that stiffness at very small strains is proportional to $\mathrm{OCR}^{\mathrm{m}}$, where $m=0.25$ for London Clay (see Fig. 25(b)). This approach could be used with the brick concept, but it is less readily adapted to coarser granular soils in which density (represented by $v$ $-v_{0}$ ) is determined by effects other than precompression.

Figure 30(a) shows the behaviour of the model in one-dimensional consolidation and swelling. The consolidation curve is linear in $v, \ln (s)$ space, but the swelling line curves slightly. At the beginning of swelling, at the reversal of the strain path, the stiffness is much higher than is given by normal use of the constant $\kappa$. Higher stiffness is also shown by a gradual flattening of the curve at high overconsolidation ratio.

The stress path for one-dimensional consolidation and swelling (Fig. 30(b)) has a typical form, returning to the origin at low stress with a gradient given by the inverse of the formula for one-dimensional normal consolidation. Broms (1971) suggested that $K_{0}$ for heavily overconsolidated soils would be the inverse of its value in normal consolidation and this occurs in the model, so $K_{0}$ tends to $\left(\sqrt{ } 2+\sin \phi^{\prime}\right)$ ! $\left(\sqrt{ } 2-\sin \phi^{\prime}\right)$. However, because of overconsolidation, the angle of shearing resistance $\phi^{\prime}$, 
which was constant during normal consolidation, increases during unloading. For the data used here, the S-shaped curve dictates that during normal consolidation the angle of shearing resistance is $22^{\circ}$, of which about $15^{\circ}$ is mobilized in one-dimensional consolidation. In the overconsolidated state the peak angle of shearing resistance exceeds $40^{\circ}$, and the maximum value mobilized in one-dimensional swelling exceeds $30^{\circ}$, corresponding to a value of $K_{0}$ of about 4 .

Figure 30(c) shows the computed relationship between $K_{0}$ and final vertical effective stress, which follows the form proposed by Meyerhof (1976) $\left(K_{0}=K_{\mathrm{rc}} \mathrm{OCR}^{0.5}\right)$, conforming more closely with the more recent findings of Mayne \& Kulhawy (1982) $\left(K_{0}=K_{\mathrm{nc}} \mathrm{OCR}^{\sin \phi^{\prime}}\right)$. The computcd rclationship is sensitive to the value of $\kappa$. In early work $\kappa=0.04$ was used, taken from Schofield \& Wroth (1968); this was found to give rather high values for $K_{0}$ in the early stages of overconsolidation. Oedometer tests carried out for the British Library project gave a wide scatter with an average value of $\kappa$ of 0.014 . The value used in this Paper is 0.02.

Figure 31(a) shows a stress path computed for one-dimensional consolidation and swelling followed by undrained shearing. In the overconsolidated state the model in its present formulation displays more strength in the compressive (active) state than in extension. As a result, the undrained test in Fig. 31(a) reaches failure at $s=251 \mathrm{kPa}, t=159 \mathrm{kPa}$. If this were onc of a scrics of laboratory test results interpreted to have $\phi^{\prime}=26^{\circ}$, it would require $c^{\prime}=54$ $\mathrm{kPa}$, a rather high value for $c^{\prime}$ in London Clay.

Figure 31(b) shows the relationship between the secant undrained Young's modulus, secant $E_{\mathbf{u}}$ and strain for the undrained test $A B C$ in Fig. 31(a). $E_{\mathrm{u}}$ has been normalized by dividing by $s_{0}$, the value of $s$ at point A. This is compared with results from triaxial tests reported by Jardine et al. (1985) and others carried out on recent projects for Arup Geotechnics. For the triaxial tests the origin of strain is generally taken at zero shear stress but the details of the recent stressstrain history are unclear. The results from the BRICK model can be plotted in different forms, according to the choice of origin of 'axial strain', taken to be $\frac{2}{3} \gamma$. If the origin is taken as point $\mathrm{A}$ on Fig. 31(a), the brick model gives a slightly higher stiffness than that measured for the practical range of strains; however, if it is taken at zero shear stress (point B), the BRICK model gives a stiffness towards the lower end of the measured range. In general therefore, the model brackets the observed results in a sensible manner, although it shows lower stiffness at shear strains less than $0.01 \%$. The parameters of the model were derived mainly from tests on reconstituted

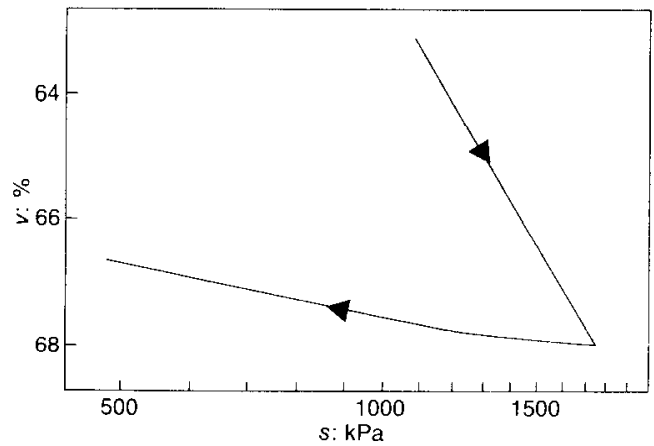

(a)

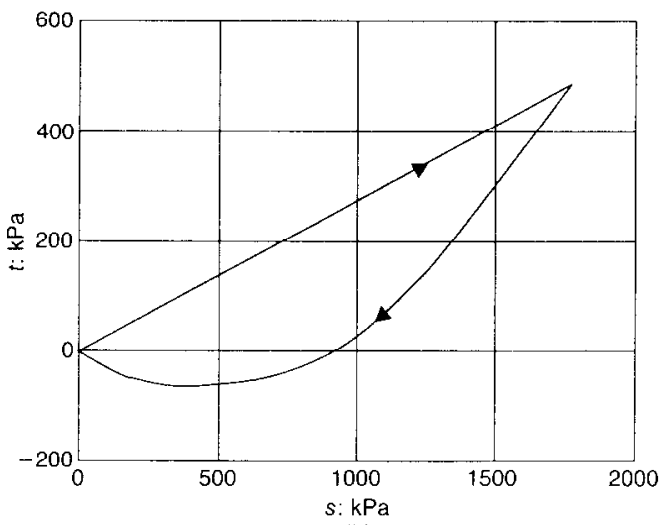

(b)

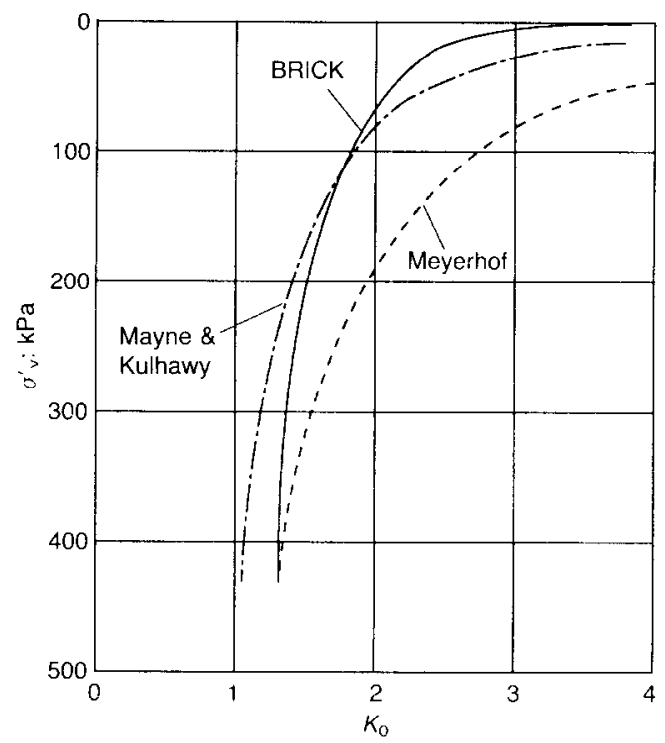

(c)

Fig. 30. BRICK predictions for one-dimensional consolidation and swelling 


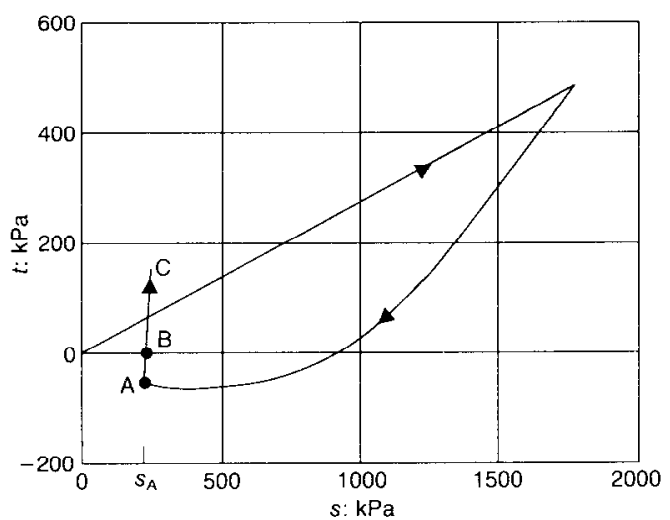

(a)

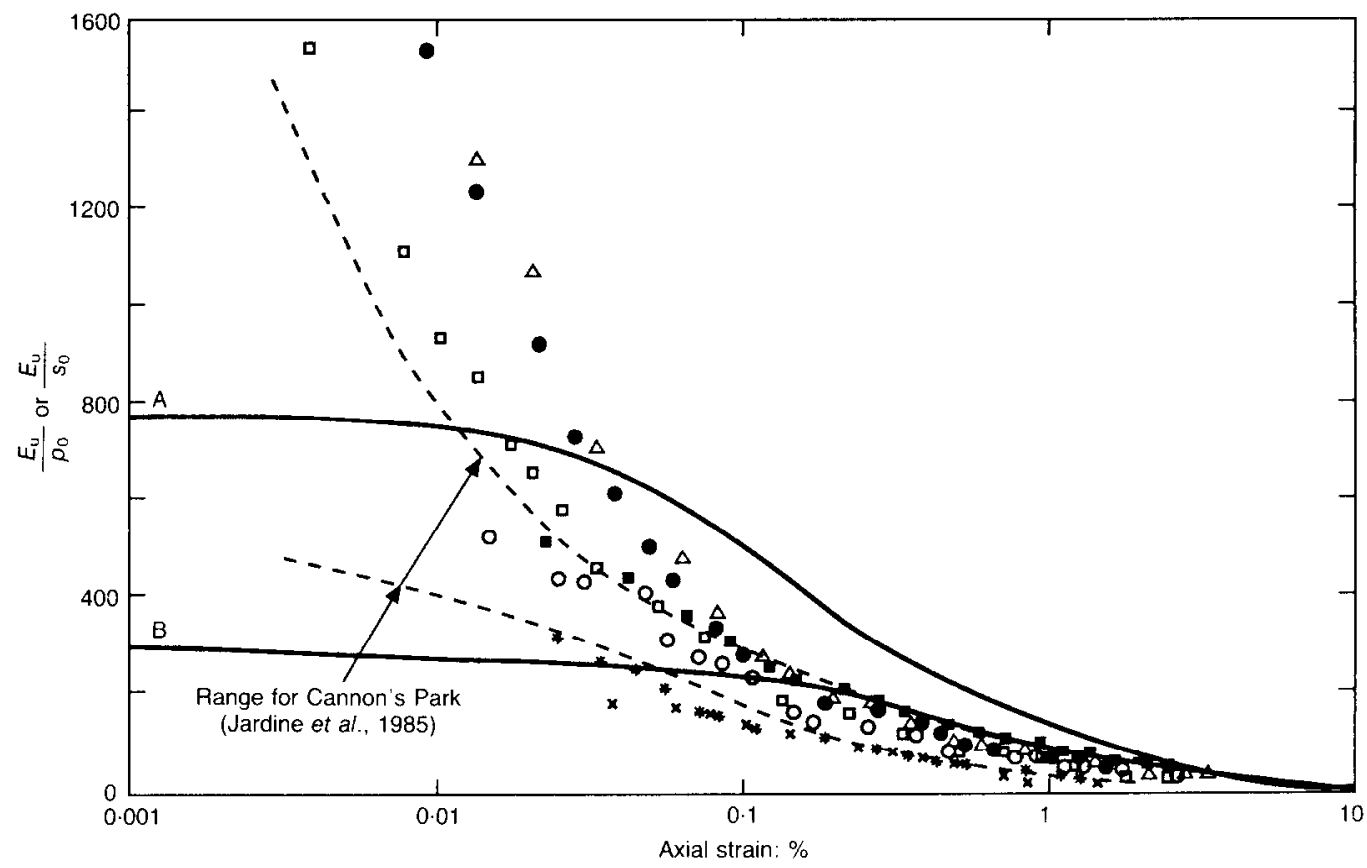

(b)

Fig. 31. One-dimensional consolidation and swelling followed by undrained shearing

samples and it may be that this is not appropriate for extremely small strains.

\section{USE OF THF BRICK MODEL IN A FINITE ELEMENT PROGRAM}

The BRICK model is ideal for use in a finite element program because, unlike most plasticity models, it derives stress increments from strain increments. The model itself requires about 80 executable lines of Fortran and an additional program is needed to set up initial states of stress and strain, including the initial positions of the 'bricks'. The basic subroutine used to derive stress increments from strain increments is presented in Appendix 1. The model has been found to be very easy to use, invariably giving good convergence and smoothly distributed stress and strain fields. It has been implemented for use in both Dos and UNIX versions of the Arup Geotechnics program SAFE, using eight-node plane strain elements with four integration points. Undrained behaviour is modelled as described by Simpson et al. (1979). At the start of each computation the geological 
history of the soil is reproduced, considering consolidation from a slurry to maximum overburden and subsequent unloading. This computation is carried out only once for each stratum; the results are stored as a function of OCR for use throughout the stratum.

\section{The British Library excavation}

For the British Library site, Fig. 32 shows predictions for $K_{0}$ during the geological history of the site taken from SAFE. After erosion of an assumed $200 \mathrm{~m}$ of overburden, $K_{0}$ would be very high. The placement of fill over the clay and subsequent underdrainage into the aquifer below increase the horizontal effective stress slightly but reduce $K_{0}$, its ratio with vertical effective stress. The final value of $K_{0}$ is comparable with other theoretical derivations (Simpson et al. 1981) and is probably more reasonable than the constant 1.8 used in earlier work.

The BRICK model has been used in the same finite element mesh and sequence of excavation as described earlier with the parameters listed in Table 1. The computed displacements (Fig. 33) are slightly greater than the measured values, but the agreement is encouraging, especially since no site-specific small strain data are available for this site. The agreement is better at the basement 3 level, before the rather tightly controlled excavation to basement 4 in the Woolwich and Reading Beds which could only be represented very roughly in the computations. In deriving curve 1 in Fig. 33(b), it was assumed that the B4 slab was placed before the removal of a small berm, $3.3 \mathrm{~m}$ high, around the perimeter of the basement. For curve 2 the floor slab was modelled as being in place before the final $3.3 \mathrm{~m}$ of excavation took place.

The computed and measured ground movements for a section through the south wall of the site are shown in Fig. 34. The two patterns of displacement compare well, but the computed displacements are generally slightly larger.

\section{An excavation in soft clay}

Initial testing of the brick model suggested that it represents the behaviour of soft clays reasonably well, so it was of interest to carry out a computation for an excavation in the soft clay of Singapore which, like London Clay, is of marine origin and has similar plasticity.

Figure 35 is an east-west cross-section through the basement of a recently completed development for the United Overseas Bank, located adjacent to the Singapore River. The construction of the basement and details of design and ground movements have been published by Wallace,

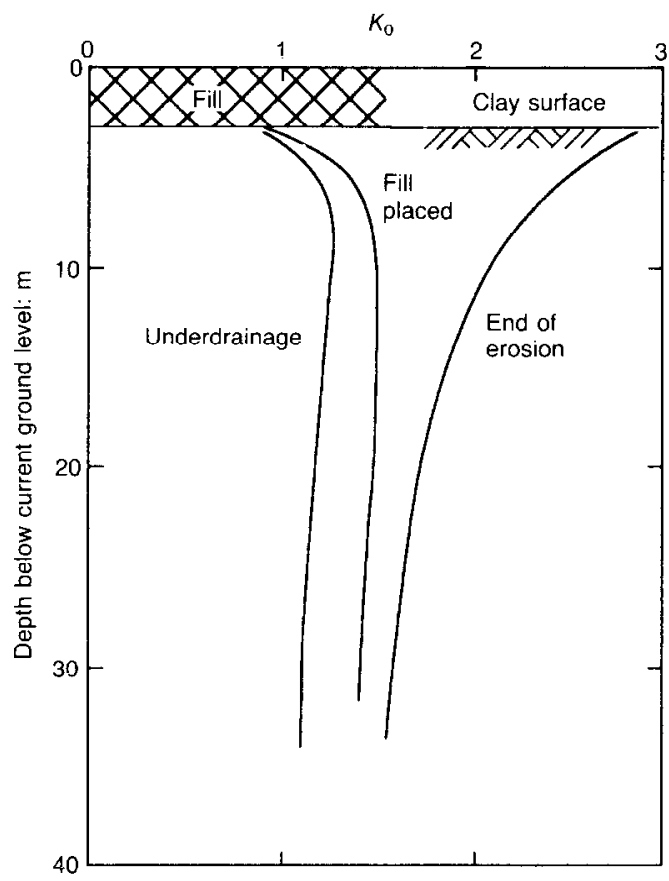

Fig. 32. $K_{0}$ compared for British Library by SAFE

Long \& Ho (1993). The geology varies across the site, with a deep deposit of the soft marine clay in the region of section $B B$, for which wall displacements were measured. The soft clay overlies much stiffer soils and is split into two layers by a desiccated layer of firm clay and sand. Fig. 36 shows that the site is about $140 \mathrm{~m}$ long and about $60 \mathrm{~m}$ wide at section BB. Close to the centreline of this section there is a group of $4 \cdot 7-6.8 \mathrm{~m}$ diameter caissons which may have restricted ground movement to some extent.

Figure 37 shows the undrained strengths measured by field vane tests and unconsolidated undrained triaxial tests. These suggested that the shear strength was higher than the model would give using the parameters listed in Table 1 for normally consolidated London Clay. The measured angles of shearing resistance were also approaching $30^{\circ}$ so a different set of parameters which had been used at an earlier stage to represent London Clay was adopted, as listed in Table 1. Fig. 38 shows one of a series of test runs of the model used to find the degree of overconsolidation required to give the measured undrained strengths. It was concluded that the apparent overconsolidation could be modelled as an additional vertical effective stress of $72 \mathrm{kPa}$ causing preconsolidation. This effect might have been caused by secondary consolidation; alternatively, other parameters of the model would 


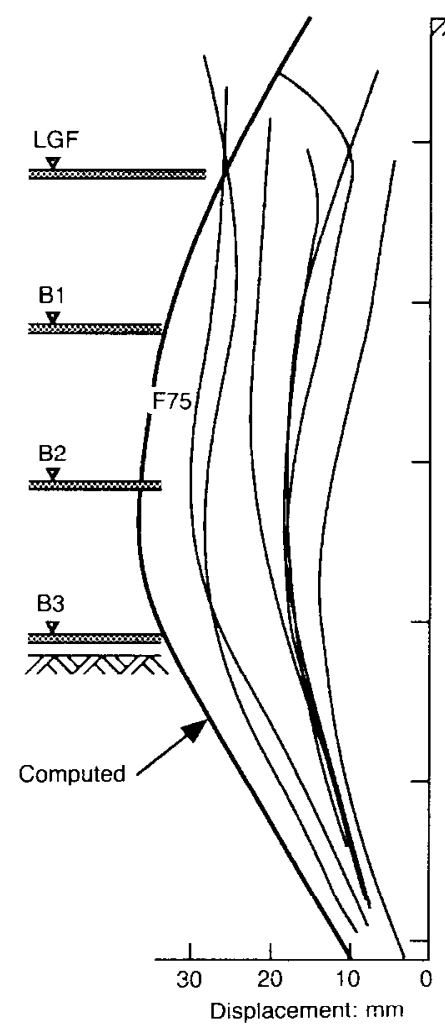

(a)

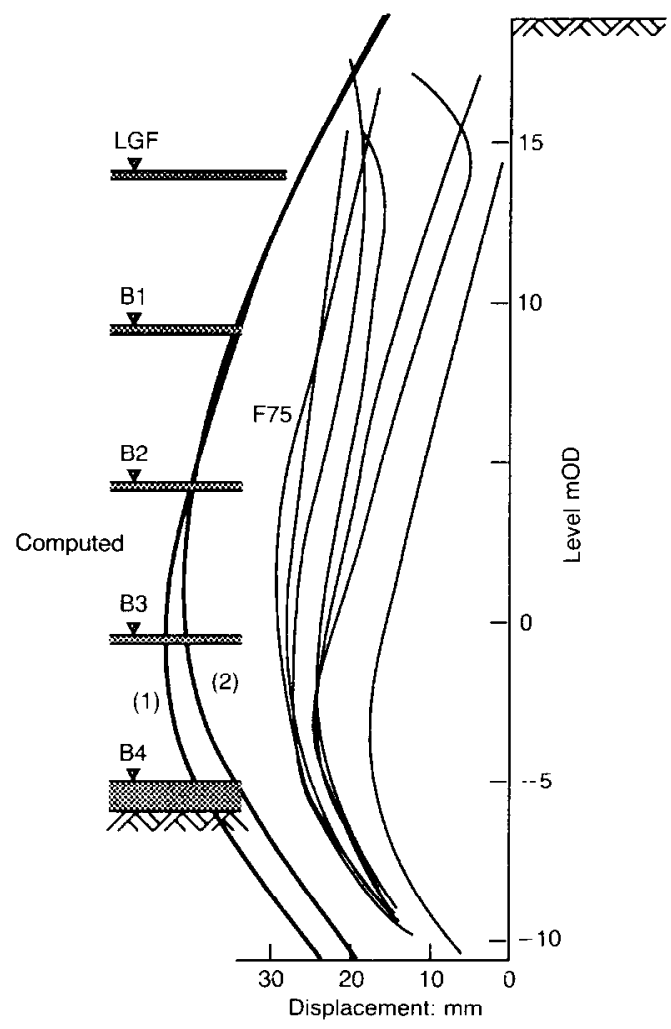

(b)

Fig. 33. BRICK computed wall movements (thick lines) for British Library compared with measurements

require amendment to achieve the measured shear strengths. For the desiccated layer the additional preconsolidation was $550 \mathrm{kPa}$.

In order to represent the effect of the caissons near the centre of cross-section BB, the half-width of the site was limited to $15 \mathrm{~m}$, and vertical fixity was assumed on the apparent centreline. Strut stiffnesses and a small amount of prestress were taken from the work of Wallace et al. (1993). The comparison of measured and computed displace-

North

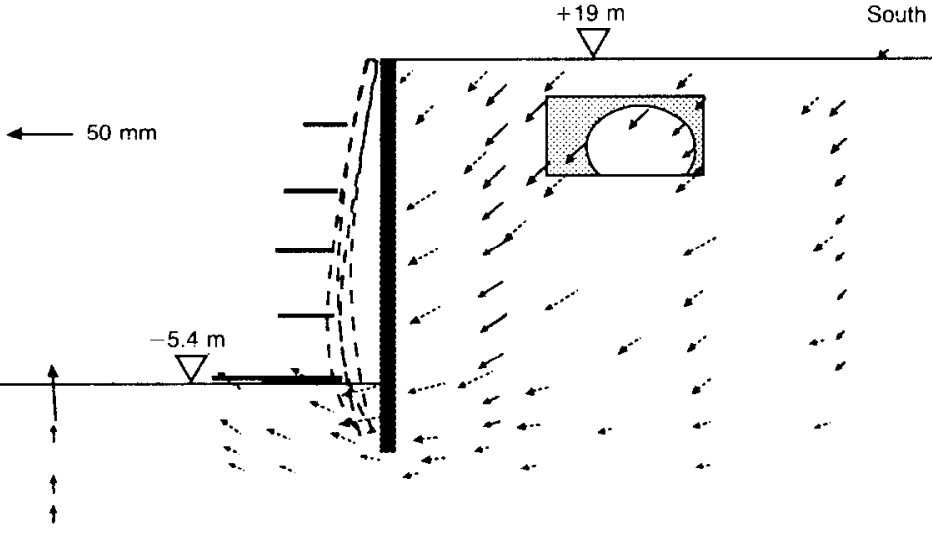

Fig. 34. BRICK computed ground displacements for British Library compared with measurements (computed results shown dotted) 


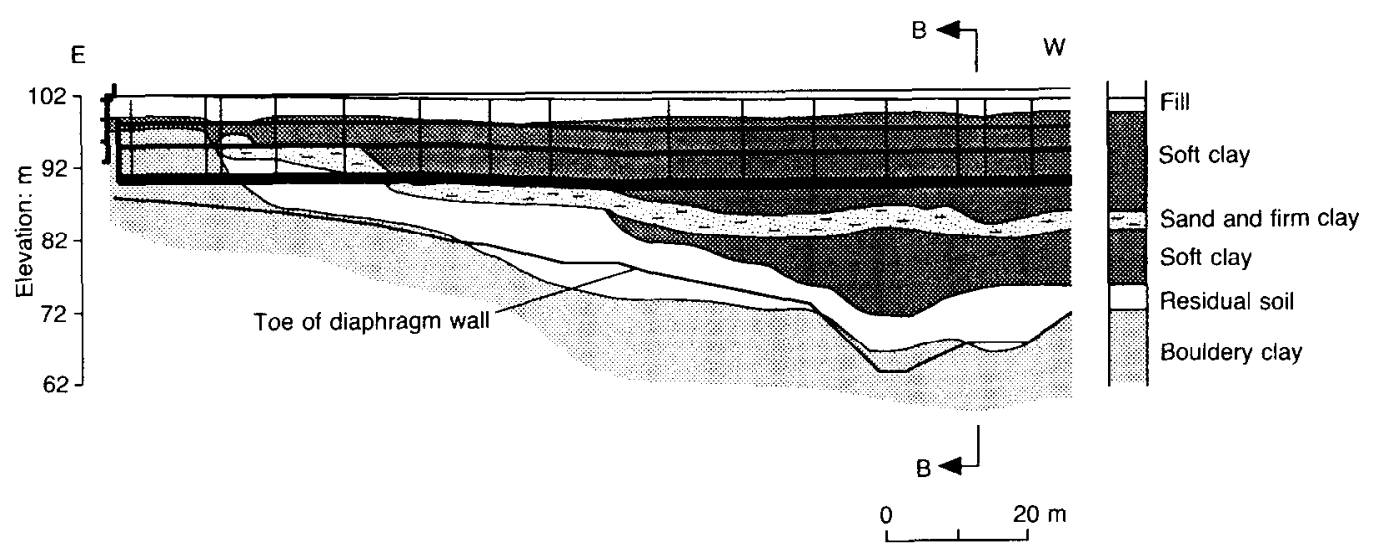

Fig. 35. Cross-section through the UOB project, Singapore

ments shown in Fig. 39 indicates that the BRICK model represents the overall behaviour of the ground quite well, assuming undrained behaviour. More detailed measurements of ground movements are not available, but the magnitude and shape of the wall movements is well reproduced. The parameters used here are similar to those for London Clay; the main difference lies in the stress history of the site.
Figure 40 shows the vector pattern of undrained movement in which the influence of vertical fixity on the apparent contreline is clear.

Other applications of the model

The original reason for developing the model was to back-analyse an excavation in Gault Clay, and results of this work will shortly be published

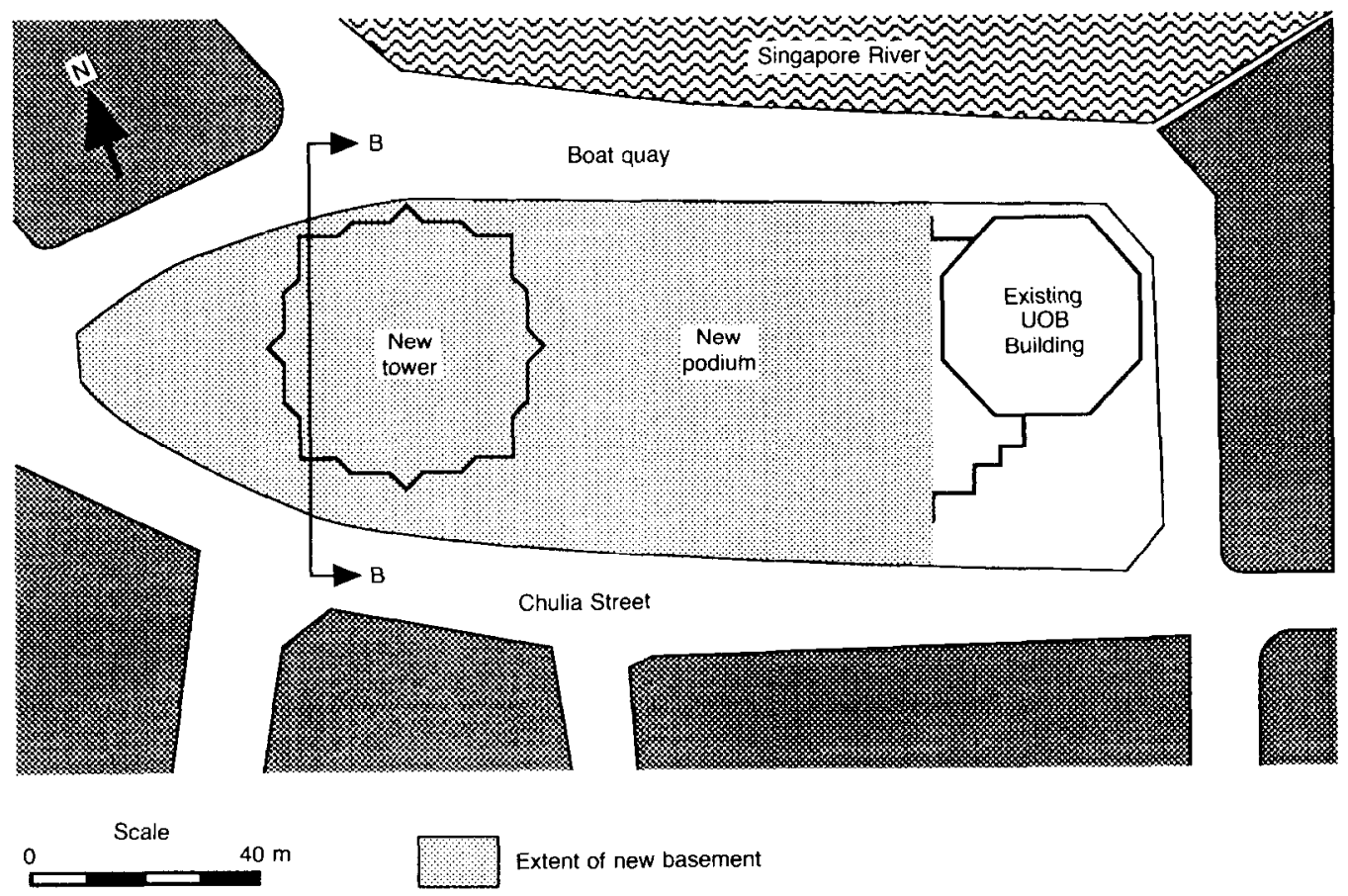

Fig. 36. Site plan of UOB project, Singapore 


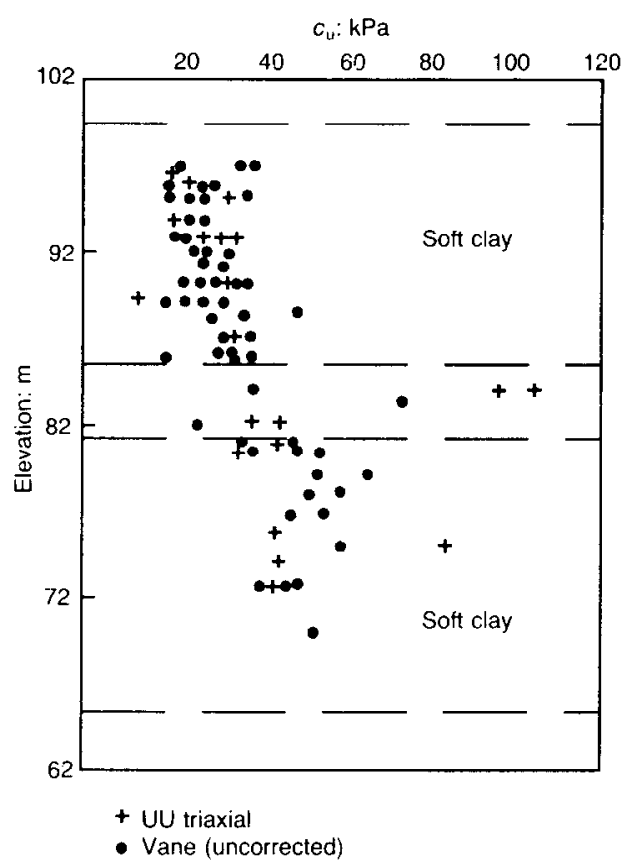

Fig. 37. Kesults of in situ vane tests for $U O B$, Singapore

by $\mathrm{Ng}(1992)$. Since there has been little research in Gault Clay, it is more difficult to be confident about parameter values, so values have been derived by fitting the model to the results of field testing, including dynamic tests.

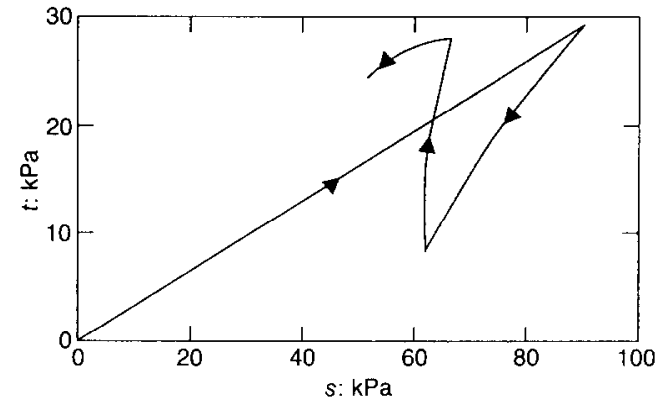

Fig. 38. One-dimensional consolidation and swelling followed by undrained shear for Singapore soft clay at elevation $92 \mathrm{~m}$

The finite element program is not limited to excavations and the BRICK model is now in use for problems including foundations, tunnels, interpretation of field testing and so on. Simpson (1992) presents a successful application to backanalysis of pressuremeter tests.

\section{FACTORS OF SAFETY RELATED TO NON-LINEAR BEHAVIOUR}

The development of non-linear models such as BRICK makes it possible to investigate the effects of varying wall lengths and so to check the effects of changing the factor of safety used in equilibrium calculations. Fig. 41 shows displacement vectors for the $8 \mathrm{~m}$ excavation considered earlier, assuming a $1 \mathrm{~m}$ thick concrete wall $(E=20 \mathrm{GPa})$
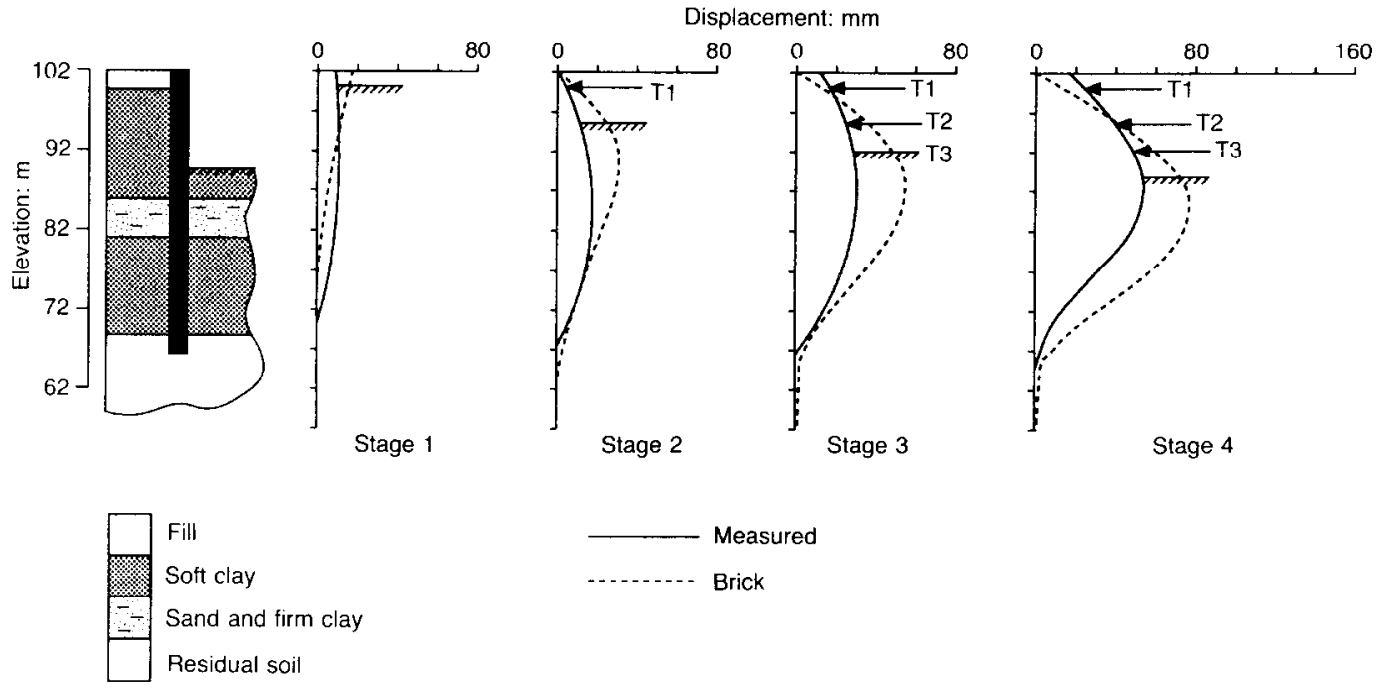

Measured

Brick

Fig. 39. Measured and computed wall displacements for UOB, Singapore 


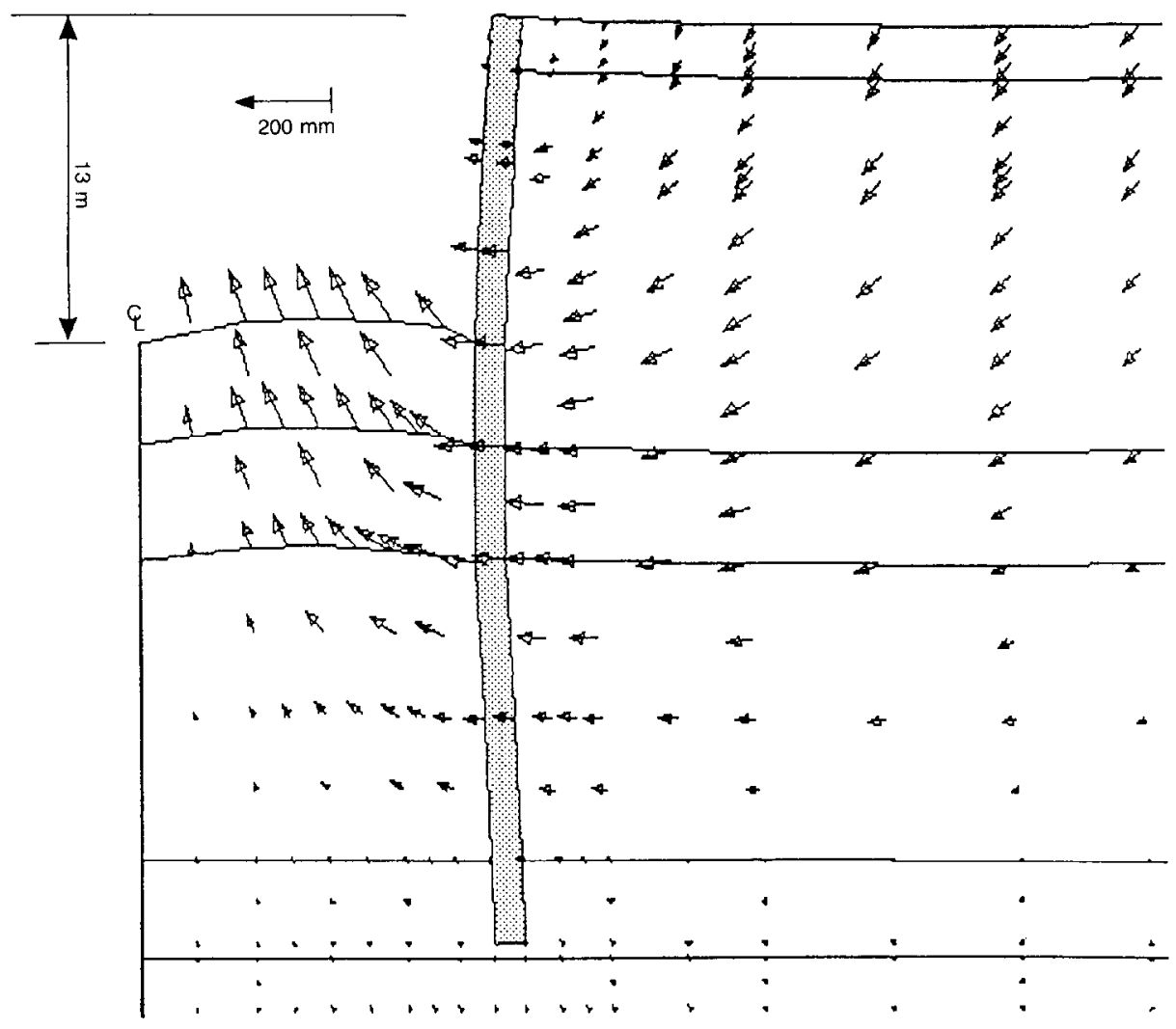

Fig. 40. Computed displacement vectors for UOB, Singapore

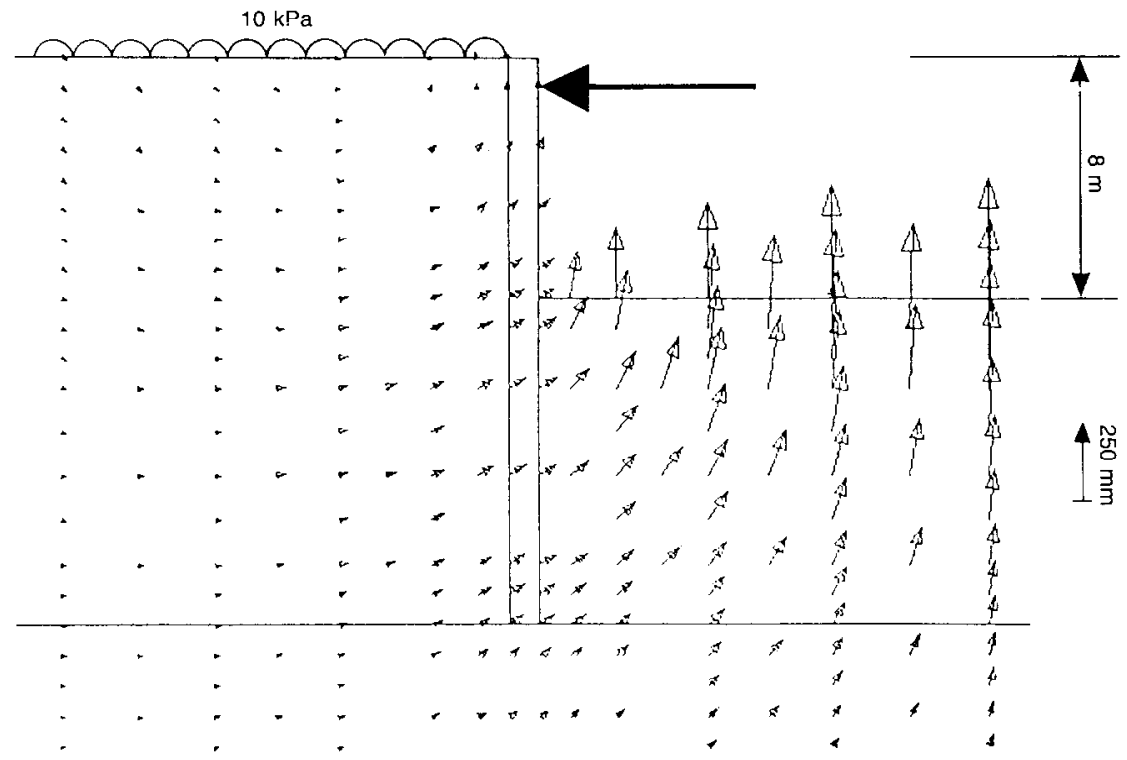

Fig. 41. Displacement vector for $8 \mathrm{~m}$ deep excavation 


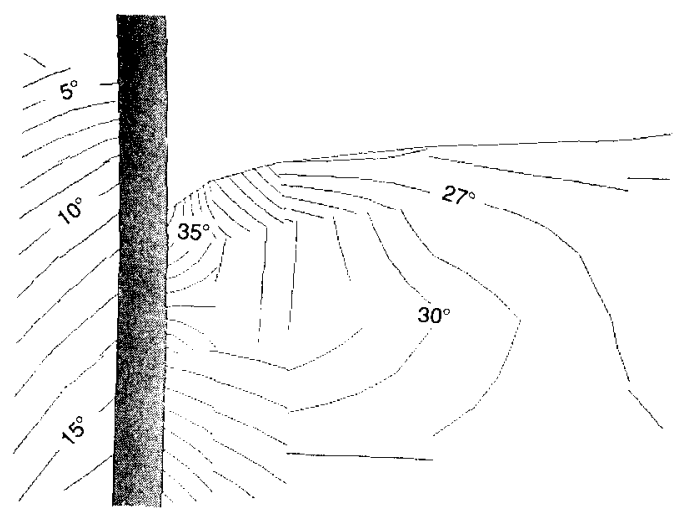

Fig. 42. Contours of $\phi_{\text {mob }}^{\prime}$ at the junction of the retaining wall and excavated surface

and using BRICK with parameters similar to those for London Clay in Table 1. A detail of the junction of the wall with the excavated surface is shown in Fig. 42, showing mobilized angles of shearing resistance. Although this model in its normally consolidated state has an angle of shearing resistance of only $20^{\circ}$, much higher angles are mobilized at the excavated surface in the overconsolidated clay. In the light of recent studies of the behaviour of stiff clays in this condition (Burland \& Fourie, 1985; Fourie \& Potts, 1991), these results might be quite realistic, although Stewart (1990) has suggested that the soil might be in an unstable state and that the

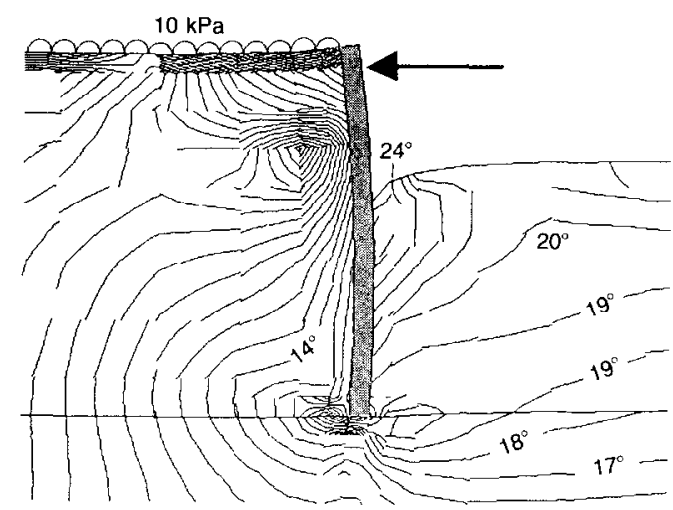

Fig. 43. Contours of $\phi_{\text {mob }}^{\prime}$ for model with maximum $\phi^{\prime}=25^{\circ}$

high resistance would not survive disturbance due to seasonal fluctuations in the ground. In the present state of knowledge it would be unwise to rely on these high angles of friction in design, and it would be difficult to relate this material to conventional factors of safety.

The parameters of the BRICK model can be modified to create a more artificial material which has a similar stiffness to that of London Clay but will fail at $25^{\circ}$. This was achieved by reducing $l$ in the ratio $\sin 20^{\circ} / \sin 25^{\circ}$ and using $\beta=0$ so that there is no additional effect of overconsolidation. Fig. 43 shows contours of mobilized $\phi^{\prime}$ for such a material. Only a small zone has

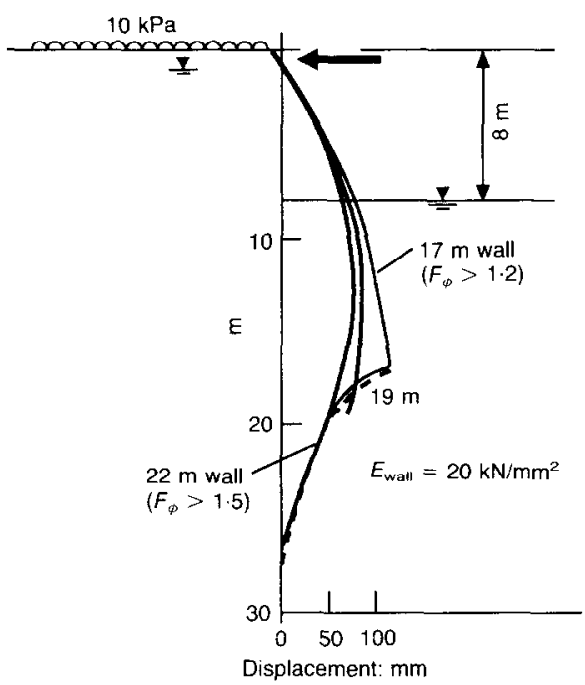

(a)

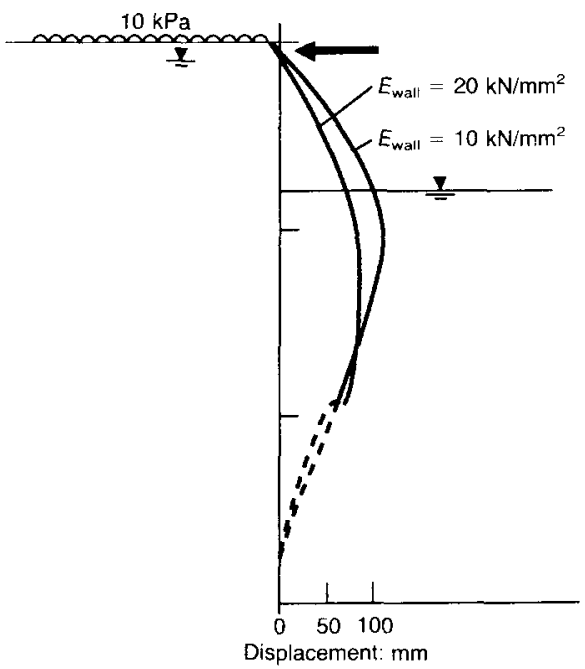

(b)

Fig. 44. Computed wall displacements for: (a) varying wall length; (b) varying wall stiffness 
reached a completely passive state, while a much larger zone has mobilized an angle of shearing resistance of more than $20^{\circ}$. In contrast, smaller angles are mobilized in the retained soil, indicating that the soil is still far from the active state. The rapidly changing contours in the upper half of the wall indicate the changes from active under the surcharge, to passive below the prop, and back towards active further down.

Figure 44(a) shows the wall lengths for different calculated factors of safety. The shorter walls are displaced further at their toes as a result of the excavation, but these computations suggest that, down to a calculated factor of 1.2 , there is little influence on the movement of the wall within the depth that would be visible or which could affect other structures.

For a constant length of $19 \mathrm{~m}$, however, Fig. 44(b) shows that halving the wall stiffness causes movements to increase rather more. This change of stiffness could represent the effect of cracking in a concrete section for example. To limit displacement it is more important to provide a stiff strong section than to add extra length.

The bending moments computed in these BRICK runs are compared with results taken from the early part of the Paper in Fig. 45; they are comparable with the results of Potts \& Fourie (1986). Shortening the wall reduces the bending moment without adding appreciably to movement, and allowing for cracking brings the bending moment back towards the values derived from the more pessimistic of the equilibrium calculations. These bending moments are not calculated for a failure state and it is necessary to decide whether they should be treated as ultimate or serviceability limit state values for design of the concrete section. This subject is under discussion between representatives of the structural and geotechnical Eurocodes.
A set of computer runs cannot solve important problems in a final manner. However, an improved understanding of soil behaviour, represented by a variety of numerical models now available, can help to clarify these difficult questions about validity of factors of safety-or factors of serviceability-in codes of practice. More work of this sort is needed in support of the codes, together with model testing especially centrifuge tests - used in parallel to ensure that the computer does not mislead us.

\section{CONCLUSION}

Understanding of the behaviour of soils and our ability to model it numerically have developed considerably in the past 15 years. This has been possible because of the extensive programmes of field measurements which have been undertaken, combined with a return to the laboratory to study the fundamentals of soil behaviour. In this Paper, a new constitutive model has been described which has gained from the work of many researchers.

The initial purpose of the BRICK model was to represent small strain effects in stiff clay, but it seems to reproduce a much wider range of features of the known behaviour of soils. The response to abrupt changes in stress path follows naturally from the analogue and it required fairly minor additions, using well established theories, to make a more complete model. Failure at constant $\phi^{\prime}$ and the value of $K_{0}$ for normal consolidation were not explicitly included in the model but were predicted by it. The same model appears to be applicable to both stiff and soft clays, and the Author suspects that the concept could be extended to granular materials as well.

Because the basic process of the model is to derive stresses from strains, it is easy to use in a

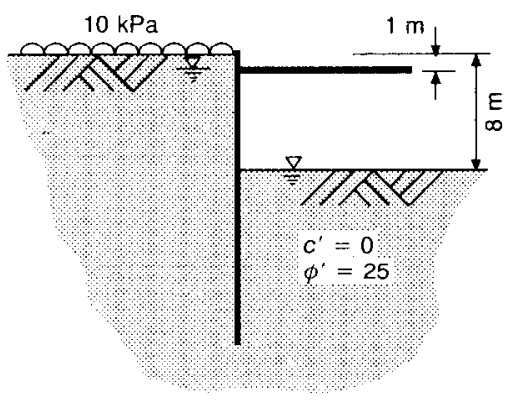

\begin{tabular}{|c|c|c|}
\hline $\begin{array}{l}\text { Factor of } \\
\text { safety }\end{array}$ & $\begin{array}{l}\text { Length: } \\
\mathrm{m}\end{array}$ & $\begin{array}{l}\text { Bending moment } \\
M: \mathrm{kNm} / \mathrm{m}\end{array}$ \\
\hline $\begin{array}{l}F=1 \\
F_{p}=2 \\
F_{\phi}=1.5 \\
F_{\phi}=1 \cdot 2 \\
\text { CIRIA } 104\end{array}$ & $\begin{array}{l}15 \cdot 2 \\
21 \cdot 8 \\
21 \cdot 3 \\
17 \cdot 4 \\
21 \cdot 3\end{array}$ & $\begin{array}{l}M_{1}=1148 \\
2255 \\
2510 \\
1550 \\
1722 \\
\text { Potts \& Fourie }\end{array}$ \\
\hline $\begin{array}{l}F_{\phi}=1 \cdot 2 \\
10 \% \text { extra } \\
\quad \text { excavation }\end{array}$ & $19 \cdot 5$ & 2117 \\
\hline Brick results & $\begin{array}{l}22.0 \\
19 \cdot 0 \\
17 \cdot 0\end{array}$ & $\begin{array}{l}2773 \\
2613 \\
2335\end{array}$ \\
\hline Cracked wall & $19 \cdot 0$ & 2178 \\
\hline
\end{tabular}

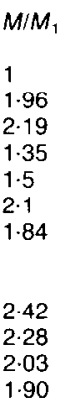

$2 \cdot 28$

$2 \cdot 03$
$1 \cdot 90$

Fig. 45. BRICK results compared with other theories for $8 \mathrm{~m}$ excavation 
finite element program. Computed results for two deep excavations have been shown here and it has also been applied to a range of construction situations and to the interpretation of in situ test results.

It has been argued that current British design methods for embedded retaining walls in stiff clays lead to walls which are unnecessarily long but may not be sufficiently strong or stiff. Calculations using the work of Bolton, Powrie \& Symons $(1990 \mathrm{a}, \mathrm{b})$, together with finite element studies using the BRICK model suggest that using shorter walls would not lead to significantly greater displacement, but displacement is sensitive to the practical range of wall stiffness.

Geotechnical engineers are fortunate in having to design a challenging range of structures built on or within a fascinating set of materials. We shall continue to rely on the fruitful interaction of field measurement, fundamental research and analytical computation.

\section{ACKNOWLEDGEMENTS}

A large number of people gave magnificient support in the preparation of this lecture; and beyond people, I have been particularly aware throughout the whole period of the very caring involvement of God in my life. I want to thank my wife and family for their consistent cncouragement, and I am grateful to my colleagues at Arup Geotechnics, particularly Milan Dedic, Qun Shi, Andrew Lord and Martyn Stroud. I am grateful for data and much assistance provided by John Atkinson, Sarah Stallebrass and Giullia Viggiani at City University, and for useful discussions with Ian Symons and Malcolm Bolton, together with the working groups of the Eurocode and the BSI code. The permission of the Department of the Environment, PSA Services to use data from British Library is gratefully acknowledged. Finally, I am particularly grateful to three mentors: Peter Wroth, David Henkel, and my father who taught me mathematics and also tried hard to teach me that the best ideas are basically very simple.

\section{APPENDIX 1. THE BRICK SUBROUTINE}

C SUBROUTINE BRICK

C

C

C The heart of the BRICK model

C Derives stress increment from strain increment

C

c

INPUT

C

C For error messages only:

\begin{tabular}{|c|c|c|}
\hline C & IE & element number \\
\hline C & IG & Gauss point no. \\
\hline C & JMAT & material zone \\
\hline C & IWL & output device \\
\hline \multicolumn{3}{|l|}{ c } \\
\hline $\mathrm{C}$ & FGK & function of Poisson's ratio $=\left(1-2^{*} n u\right)$ \\
\hline $\mathrm{C}$ & & $=$ ratio of elastic shear modulus \\
\hline c & & to plane strain bulk modulus \\
\hline C & RLAM & lambda \\
\hline C & RKAP & kappa \\
\hline C & RIOT & iota \\
\hline $\mathrm{C}$ & BETA & beta - parameter for OCR effect on stiffness \\
\hline C & EXPO & exponent of mean normal stress in stiffness law \\
\hline C & & NB only EXPO $=1$ has been tested \\
\hline $\mathrm{C}$ & NC & number of components of stress and strain \\
\hline
\end{tabular}


C

C

C

C

C

C

C

C

C

C

C

C

C

C

C

C

C

C

C

C

C

C

C

C

C

C

C

C

C

C

C

C

C

C

C

SUBROUTINE BRICK (IE,IG,JMAT,IWL,

$*$

C

DIMENSION SS $\left({ }^{*}\right), \operatorname{SN}\left({ }^{*}\right), \operatorname{SL}\left({ }^{*}\right), \operatorname{SNB}\left(\mathrm{NCD},{ }^{*}\right), \operatorname{DSNP}\left({ }^{*}\right), \operatorname{SNBP}(20)$,

* $\operatorname{DSN}\left({ }^{*}\right), \operatorname{DSS}\left({ }^{*}\right), \operatorname{PSRED}\left({ }^{*}\right), \operatorname{DSNB}\left(\mathrm{NCD},{ }^{*}\right), \operatorname{SNT}\left({ }^{*}\right), \operatorname{SSM}\left({ }^{*}\right)$,

c

$\mathrm{C}$

$\mathrm{C}$

$\mathrm{NC}=3$ used in plane strain

1 : (plane strain) mean stress and volumetric strain

2: difference of $y$ and $x$ direct stresses and strains

3: Tau-xy and Gamma-xy

These components are used for $\mathrm{SS}, \mathrm{SN}$ etc

dimension of $\mathrm{NC}$ in calling routine

stress before increment

$\mathrm{SS}(1)$ - mean stress $\mathrm{SS}(2 \mathrm{etc})$ - shear stress

strain before increment

$\mathrm{SN}(1)$ - vol strain $\mathrm{SN}(2$ etc) - shear strain

increments of $\mathrm{SN}$

(1) initial $S N(1)$

(2) initial SS(1)

tolerance for stress convergence

number of bricks

string lengths for each brick

G/Gmax for each brick

SNB (NCD, NB) strains for each brick before increment

$\operatorname{VOLP}(2)$

(1) current volumetric plastic strain

(2) max previous vol plastic strain

WORKING SPACE

$\mathrm{SNT}(\mathrm{NCD})=\mathrm{SN}+\mathrm{DSN}$

PSRED(NCD) additional elastic strain ( = "plastic strain

reduction") due to increased mean stress (or vice versa)

$\mathrm{SSM}(\mathrm{NCD}) \quad$ mean values of SS during increment

SNBP(NB) strain proportions for each brick

RIOTBB RIOT modified for BETA term

BETMOD

BETA modification factor to RIOT for shortest string

OUTPUT

DSS(NCD) stress increments

DSNP(NCD) plastic strain increments

DSNB (NCD,NB) strain increment for each brick

FGK, RLAM, RKAP, RIOT,BETA,EXPO,NC,NCD,SS,SN,DSN

ZERO,TOLBR,NB,SL,GGMAX,SNB,VOLP,SNT,PSRED,SSM,

DSS,DSNP,DSNB)

* $\operatorname{VOLP}(*), Z E R O\left({ }^{*}\right), G G M A X(*)$

Initialise

RIKAP $=$ RIOT $/($ RKAP - RIOT $)$

RILAM $=$ RIOT $/($ RLAM - RIOT $)$ 


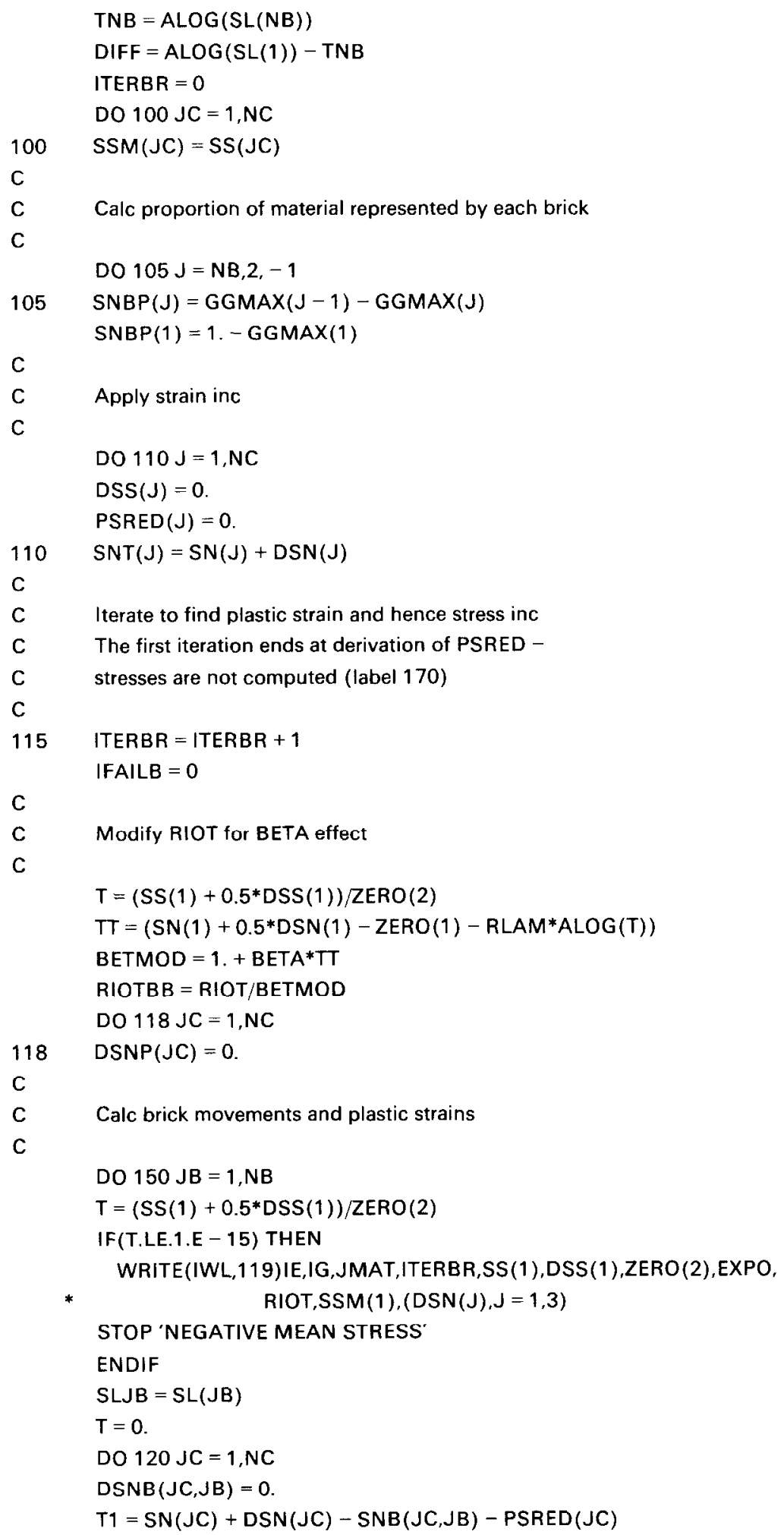




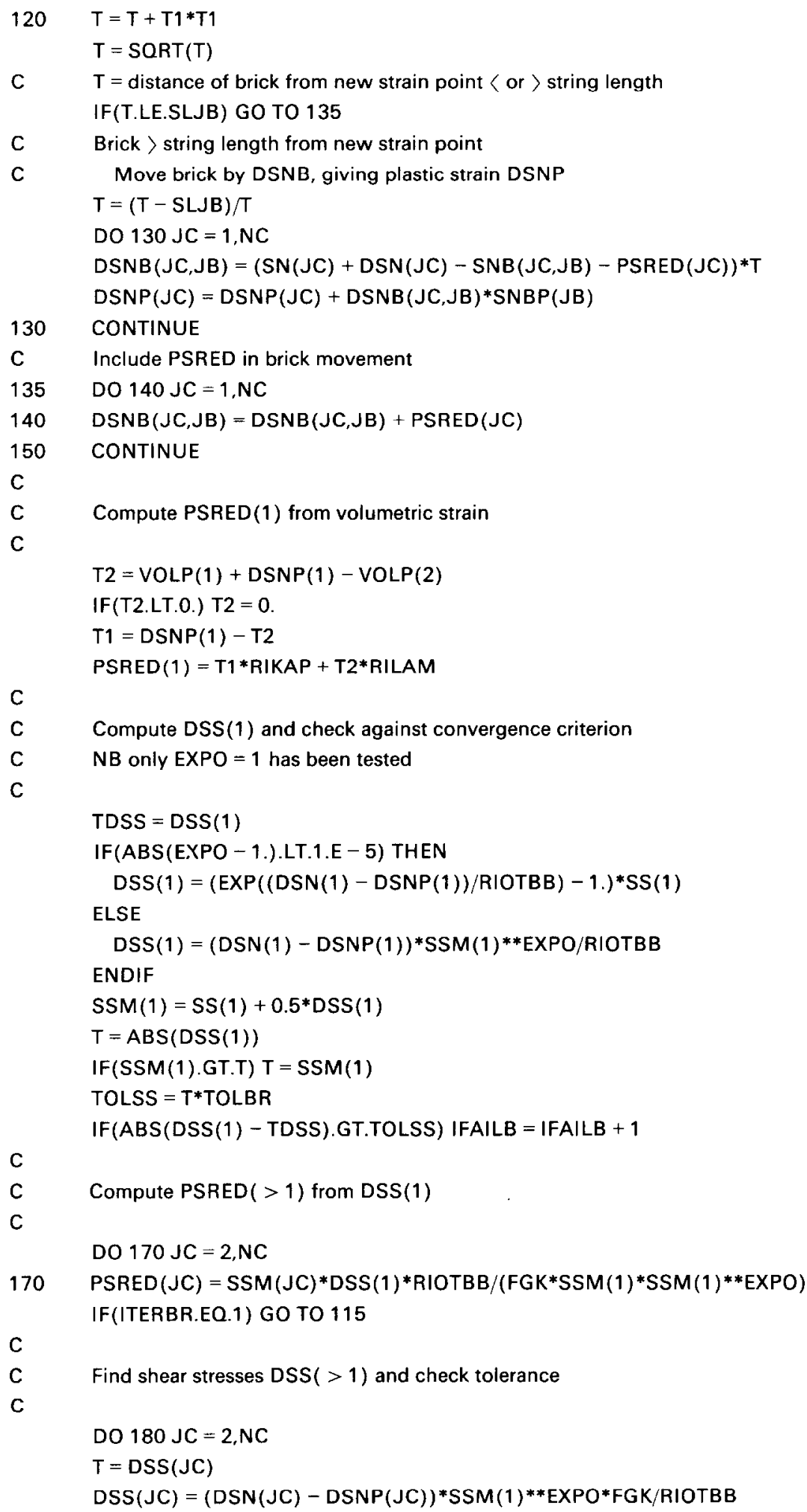




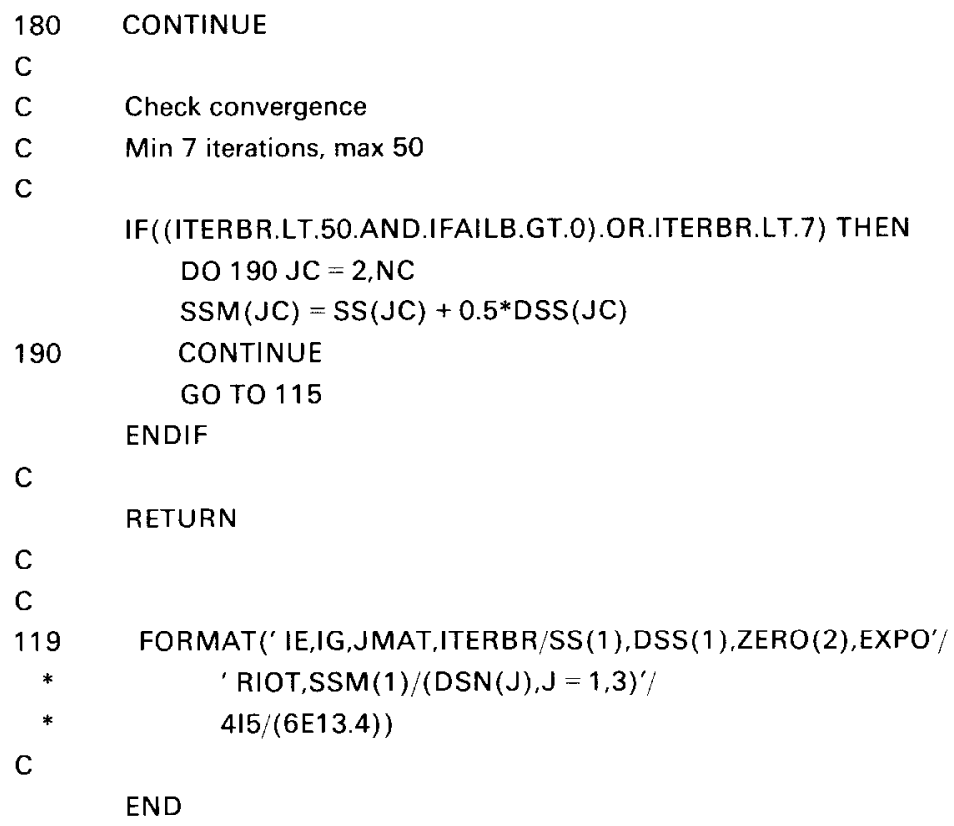

C

END

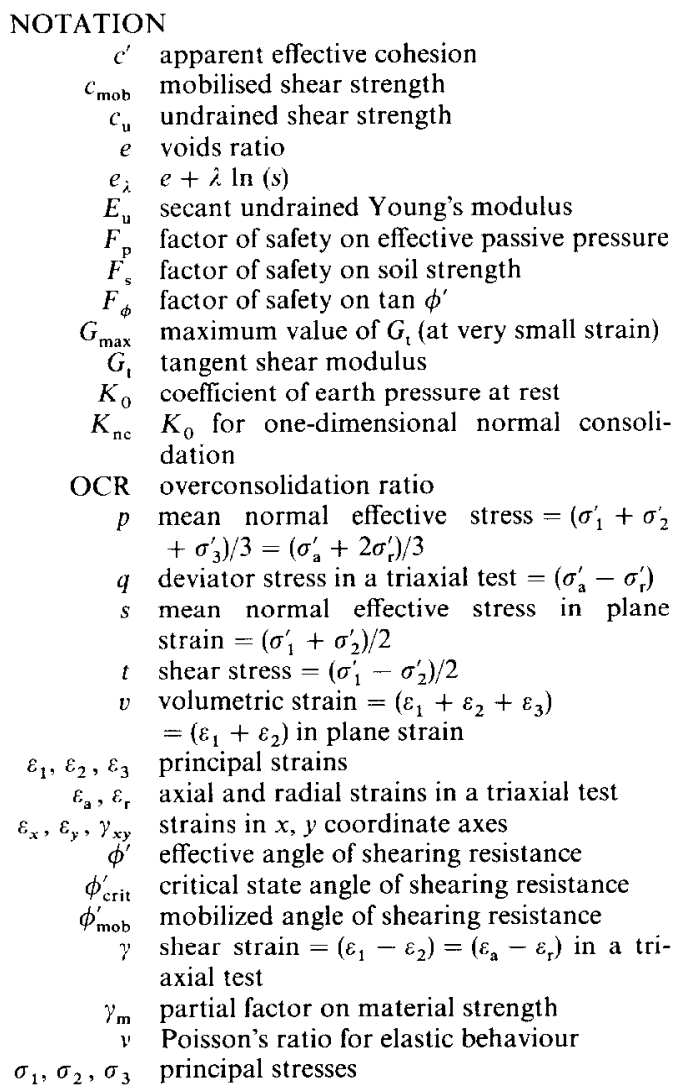

$$
\begin{array}{ll}
\sigma_{\mathrm{a}}^{\prime}, \sigma_{\mathrm{r}}^{\prime} & \begin{array}{l}
\text { axial and radial effective stress in a triaxial } \\
\text { test }
\end{array} \\
\lambda, \kappa, l, \beta & \text { constants in the BRICK soil model. }
\end{array}
$$

Subscripts

e elastic component of strain

p plastic component of strain

The parameters $\lambda, \kappa$ and $l$ used in this Paper are equivalent to $\lambda^{*}$ and $\kappa^{*}$ as discussed by Houlsby \& Wroth (1991), as they are defined in terms of volumetric strain $v$ rather than voids ratio.

\section{REFERENCES}

Al Tabbaa, A. (1987). Permeability and stress strain response of speswhite kaolin. $\mathrm{PhD}$ thesis, University of Cambridge.

Al Tabbaa, A. \& Wood, D. M. (1989). An experimentally based 'bubble' model for clay. Proc. 3rd Int. Conf. Numer. Meth. Geomech. 3, 91-99. Barking: Elsevier Applied Science.

Atkinson, J. H. \& Sallfors, G. (1991). Experimental determination of soil properties (stress-strain--time). Proc. 10th Eur. Conf. Soil Mech. Fndn Engng, Florence, 3, pp. 915-958.

Balasubramaniam, A. S. (1969). Some factors influencing the stress-strain behaviour of clay. PhD thesis, University of Cambridgc.

Bolton, M. D. (1991). Geotechnical stress analysis for bridge abutment design. Transport and Road Research Laboratory Contractor Report 270. London: HMSO. 
Bolton, M. D., Powrie, W. \& Symons, I. F. (1990a). The design of stiff walls retaining overconsolidated clay: Part I, short term behaviour. Ground Engng 23, No. 1, 34-40.

Bolton, M. D., Powrie, W. \& Symons, I. F. (1990b). The design of stiff walls retaining overconsolidated clay: Part II, long term behaviour. Ground Engng 23, No. 2, 22-28.

British Standards Institution (1951). Code of practice No. 2: Earth retaining structures. London: BSI.

British Steel plc (1988). Piling handbook. London: British Steel.

Broms, B. (1971). Lateral earth pressures due to compaction in cohesionless soils. Proc. 4th Conf. Soil Mech., Budapest, pp. 373-384.

Brooker, E. W. \& Ireland, O. H. (1965). Earth pressures at rest related to stress history. Can. Geotech. J. 2, No. 1, 1-15.

Burland, J. B. (1967). Deformation of soft clay. PhD thesis, University of Cambridge.

Burland, J. B. \& Fourie, A. B. (1985). The testing of soils under conditions of passive stress relief. Géotechnique 35, No. 2, 193-198.

Burland, J. B. \& Hancock, R. J. R. (1977). Underground car park at the House of Commons: Geotechnical aspects. Struct. Engr 55, 87-100.

Burland, J. B., Potts, D. M. \& Walsh, N. M. (1981). The overall stability of free and propped embedded cantilever retaining walls. Grnd Engng 14, No. 5, 28-38.

Burland, J. B., Simpson, B. \& St John, H. D. (1979). Movements around excavations in London Clay. Proc. 7th Eur. Conf. Soil Mech., Brighton, 1, 13-30.

Society for Harbor Engineering and the German Society for Soil Mechanics and Foundation Engineering (1982). Recommendations of the Committee for Waterfront Structures. EAU 1980. Berlin: Wilhelm Ernst \& Sohn.

Fourie, A. B. \& Potts, D. M. (1991). Géotechnique 41, No. 1, 1-15.

Geotechnical Control Office (1982). Guide to retaining wall design. Hong Kong: GCO Civil Engineering Services Department.

Head, J. M. \& Wynne, C. P. (1985). Designing retaining walls embedded in stiff clay. Grnd Engng 18, No. 3, 30-33.

Houlsby, G. T. \& Wroth, C. P. (1991). The variation of shear modulus of a clay with pressure and overconsolidation ratio. Soils Fdns 31, No. 3, 138-143.

Jaky, J. (1944). The coefficient of earth pressure at rest. J. Soc. Hungarian Archit. Engrs 78, No. 22, 355-358.

Jardine, R. J., Fourie, A., Maswoswe, J. \& Burland, J. B. (1985). Field and laboratory measurement of soil stiffness. Proc. 1Ith Int. Conf. Soil Mech. Fndn Engng, San Francisco, 2, pp. 511-514.

Krebs Ovesen, N. (1984). The geotechnical design process - a comparison of practice among the Nordic countries (in Danish). Vag-och Vattenbygaren, Nos. $7-8$.

Loudon, P. A. (1967). Some deformation characteristics of kaolin. PhD thesis, University of Cambridge.

Mayne, P. W. \& Kulhawy, F. H. (1982). $K_{0}-$ OCR relationships in clay. J. Am. Soc. Civ. Engrs 108, No. GT6, 851-870.

Meyerhof, G. G. (1976). Bearing capacity and settlement of pile foundations. J. Geotech. Div. Am. Soc. Civ. Engrs 102, No. GT 3, 197-228.
Mroz, Z., Norris, V. A. \& Zienkiewicz, O. C. (1981). An anisotropic, critical state model for soils subject to cyclic loading. Géotechnique 31, No. 4, 451-469.

Newman, R. L., Chapman, T. J. P. \& Simpson, B. (1991). Evaluation of pile behaviour from pressuremeter tests. Proc. I0th Eur. Conf. Soil Mech. Fndn Engng, Florence, 2, 501-504.

Ng, C. W. W. (1992). An evaluation of soil-structure interation associated with a multi-propped excavation. $\mathrm{PhD}$ thesis, University of Bristol.

Padfield, C. J. \& Mair, R. J. (1984). Design of retaining walls embedded in stiff clay. CIRIA Report 104. London: Construction Industry Research and Information Association.

Pang, P. L. R. (1992). A limit state code for retaining wall design in Hong Kong. Retaining structures, Proc. Instn Civ. Engrs Conf., Cambridge. London: Thomas Telford.

Potts, D. M. \& Fourie, A. B. (1986). A numerical study of the effects of wall deformation on earth pressures. Int. J. Numer. Analyt. Meth. in Geomech. 10, 383405.

Richardson, D. (1988). Investigations of threshold effects in soil deformations. PhD thesis, City University, London.

Rowe, P. W. (1955). A theoretical and experimental analysis of sheet piled walls. Proc. Instn Civ. Engrs 4, Part 1, 32-69.

Schofield, A. N. \& Wroth, C. P. (1968). Critical state soil mechanics. London: McGraw-Hill.

Seed, H. B. \& Idriss, I. M. (1970). Soil moduli and damping factors for dynamic response analysis. EERC Report No. 70-10, Berkeley, California, USA.

Simpson, B. (1993). Development and application of a new soil model for prediction of ground movements. In Predictive soil mechanics, Proceedings of Wroth Memorial Symposium, Oxford. London: Thomas Telford. In press.

Simpson, B., O'Riordan, N. J. \& Croft, D. D. (1979). A computer model for the analysis of ground movements in London Clay. Géotechnique 29, No. 2, 149 175.

Simpson, B., Calabresi, G., Sommer, H. \& Wallays, M. (1981). Design parameters for stiff clays. Proc. 7 th Eur. Conf. Soil Mech. Fndn Engng, Brighton, 1979, 5, 91-125.

Skempton, A. W. \& Henkel, D. J. (1957). Tests on London Clay from deep borings at Paddington, Victoria and the South Bank. Proc. 4th Int. Conf. on Soil Mech. Fndn Engng, London, 1, pp. 100-106.

Stallebrass, S. A. (1990). Modelling the effect of recent stress history on the deformation of overconsolidated soils. PhD thesis, City University, London.

Stewart, D. I. (1990). Groundwater effects on in situ walls in stiff clay. PhD thesis, University of Cambridge.

Stroud, M. A. (1971). The behaviour of sand at low stress levels in the simple shear apparatus. $\mathrm{PhD}$ thesis, University of Cambridge.

Symons, I. F. \& Carder, D. R. (1989). Long term behaviour of embedded retaining walls in overconsolidated clay. Geotechnical instrumentation in practice, pp. 289-307. London: Thomas Telford.

Terzaghi, K. (1954). Anchored bulkheads. Trans. Am. Soc. Civ. Engrs 119, 1243-1281.

Viggiani, G. (1992). Dynamic measurement of small strain stiffness of fine grained soils in the triaxial 
apparatus. Proc. workshop on experimental characterization and modelling of soils and soft rocks, Napoli, pp. $75-97$.

Wallace, J. C., Long, M. M. \& Ho, C. E. (1993). Retaining wall behaviour for a deep basement in Singapore Marine Clay. In Retaining structures. London: Thomas Telford. In press.

Ward, W. H. \& Burland, J. B. (1973). The use of ground strain measurements in civil engineering. Phil. Trans. $R$. Soc., Series $A, 27$, No. 4, 421-428.

Wroth, C. P. (1971). Some aspects of the elastic beliaviour of overconsolidated clay. Proc. Roscoe Mem. Symp., Foulis, pp. 347-361.

\section{VOTE OF THANKS}

\section{PROFESSOR NIELS KREBS OVESEN}

Having had the privilege and stimulation of working closely with Dr Brian Simpson on Eurocode 7 for the past seven years, it gives me great pleasure to propose a vote of thanks to him for having delivered a superb 32nd Rankine Lecture. It was indeed an outstanding and most memorable lecture displaying the combination of skills of a uniquely practical engineer and gifted researcher.

The first time the international geotechnical community realized that a new star had been born on the British geotechnical sky was on the occasion of the European conference in Brighton in 1979. Dr Simpson's General report on the design parameters for stiff clays was indeed one of the highlights of that conference.

It was therefore no surprise when representatives from the then nine European Community countries met in 1981 for the first Eurocode 7 meeting to find that Dr Simpson had been selected for the task of representing the views of his British colleagues-not necessarily an easy task for an engineer of little more than 30 years of age at that time, or of any age for that matter.

Since then the committee has met for 40 two-day meetings. Whether our meetings have been successful in producing a European geotechnical code remains to be seen. They have, however, provided us, Brian Simpson's continental colleagues, with an exciting opportunity to benefil from his vast geotechnical experience and theoretical insight.

At the beginning of his lecture today Brian Simpson said that after having submitted the title, he began to wonder why he had not chosen something less demanding and less controversial. Brian, you have not only had the courage to select and to stick to a subject which we all agree is a difficult one-you have also demonstrated most eloquently that you have the faculties to make a major contribution to our understanding of some of the fundamental problems involved in the design of retaining structures.

Brian Simpson has included such topics as design and codes of practice in his Rankine Lecture and thereby he has certainly broken new grounds.

Firstly, he discussed the basis of design of retaining walls and the use of factors of safety, particularly in relation to the development of codes of practice. He underlined the importance of considering not only stresses but displacements as well in the design of retaining structures. He argued that factors of safety are not introduced only to prevent collapse, but-perhaps more importantly - to avoid the wall moving unacceptably. Furthermore, he stressed the importance of taking past experience with existing structures into account when writing codes of practice.

Secondly, Brian Simpson drew from his practical experience with the deep excavation for the new British Library. Combining field observations, laboratory test results and finite element analyses he has made a major contribution to our understanding of the stiffness of soils at small strains.

In the third and last part of his lecture Brian Simpson challenged our curiosity with his statement 'soil behaves like bricks on strings'. He took us together with his little man on a walk in strain space, and he reminded us again that stress is a philosophical concept-deformation is a physical reality. Without doubt his observation that soil behaves like bricks on strings will have significant theoretical and practical impact in the years to come.

In the first Rankine Lecture some 31 years ago Professor Casagrande stated that he would 'make use of theory to supplement empirical knowledge and to enhance sound judgment'. This is exactly what we have heard and seen Dr Simpson doing today. I feel sure that those present will agree with me that Dr Simpson's 32nd Rankine Lecture has been stimulating, thought-provoking and of extreme value. It is with the greatest pleasure that I propose a hearty vote of thanks to $\mathrm{Dr}$ Brian Simpson. 